\title{
Expert consensus document on the assessment of the severity of aortic valve stenosis by echocardiography to provide diagnostic conclusiveness by standardized verifiable documentation
}

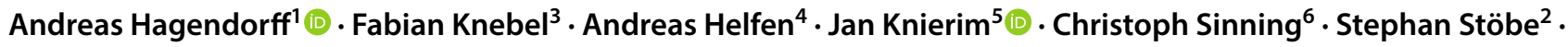 \\ Wolfgang Fehske ${ }^{7} \cdot$ Sebastian Ewen $^{8}$
}

Received: 22 June 2019 / Accepted: 14 August 2019 / Published online: 3 September 2019

(c) Springer-Verlag GmbH Germany, part of Springer Nature 2019

\begin{abstract}
According to recent recommendations on echocardiographic assessment of aortic valve stenosis direct measurement of transvalvular peak jet velocity, calculation of transvalvular mean gradient from the velocities using the Bernoulli equation and calculation of the effective aortic valve area by continuity equation are the appropriate primary key instruments for grading severity of aortic valve stenosis. It is obvious that no gold standard can be declared for grading the severity of aortic stenosis. Thus, conclusions of the exclusive evaluation of aortic stenosis by Doppler echocardiography seem to be questionable due to the susceptibility to errors caused by methodological limitations, mathematical simplifications and inappropriate documentation. The present paper will address practical issues of echocardiographic documentation to satisfy the needs to analyze different scenarios of aortic stenosis due to various flow conditions and pressure gradients. Transesophageal and multidimensional echocardiography should be implemented for reliable measurement of geometric aortic valve area and of cardiac dimensions at an early stage of the diagnostic procedure to avoid misinterpretation due to inconsistent results.
\end{abstract}

Keywords Echocardiography $\cdot$ Aortic stenosis $\cdot$ Quantification $\cdot$ Aortic valve area $\cdot$ Pressure gradient $\cdot$ Pressure recovery

\section{Introduction}

According to recent recommendations on echocardiographic assessment of aortic valve stenosis (AS) direct measurement of AS peak jet velocity $\left(V_{\max } \mathrm{AS}\right)$, calculation of

For the Working Group "Cardiovascular Ultrasound" of the German Society of Cardiology coordinated at the "1. Mitteldeutscher Echokardiographie-Kongress in Leipzig”.

Andreas Hagendorff

Andreas.Hagendorff@medizin.uni-leipzig.de

1 Department of Cardiology, University of Leipzig, Klinik und Poliklinik für Kardiologie, Liebigstraße 20, 04103 Leipzig, Germany

2 Department of Cardiology, University of Leipzig, Liebigstraße 20, 04103 Leipzig, Germany

3 Department of Cardiology and Angiology, Universitätsmedizin Berlin, Campus Charité Mitte, Charitéplatz 1, 10117 Berlin, Germany

4 Department of Cardiology, St. Marien Hospital Lünen, Altstadtstraße 23, 44534 Lünen, Germany transvalvular mean gradient $\left(\Delta P_{\text {mean }} \mathrm{AS}\right)$ from the velocities using the Bernoulli equation and calculation of the effective aortic valve area $\left(\mathrm{AVA}_{\text {eff }}\right)$ by continuity equation are the appropriate primary key instruments for grading AS severity in all patients with AS [1-5]. The calculation of the AVA $_{\text {eff }}$ by maximum left ventricular outflow tract (LVOT) velocity ( $V_{\max }$ LVOT) and $V_{\max } \mathrm{AS}$, the ratio between $V_{\max }$ LVOT and $V_{\max } \mathrm{AS}$ and the planimetry of the anatomic or geometric aortic valve area $\left(\mathrm{AVA}_{\text {geom }}\right)$ are declared as only reasonable

5 Department of Cardiovascular Surgery, University of Berlin, Deutsches Herzzentrum Berlin, Augustenburger Platz 1, 13353 Berlin, Germany

6 Department of Cardiology, University of Hamburg-Eppendorf, Martinistraße 52, 20251 Hamburg, Germany

7 Department of Cardiology St, Vinzenz-Hospital Köln, Merheimer Straße 221, 50733 Köln, Germany

8 Klinik für Innere Medizin III, Kardiologie, Angiologie Und Internistische Intensivmedizin, Universitätsklinikum Des Saarlandes, Kirrberger Str., 66421 Homburg, Germany 
when additional information is needed in selected patients. Regarding the fact that grading of the AS severity is based on only one direct measurable parameter (AS jet velocity), which is reliable only in patients with normal left ventricular (LV) function and forward LV stroke volume (LVSV), and on calculations based on the simplified Bernoulli equation and on LVOT diameter assessment by transthoracic echocardiography (TTE), which usually results in an underestimation of the normally oval shaped LVOT cross sectional area $\left(\mathrm{CSA}_{\mathrm{LVOT}}\right)$, it is obvious that no definite gold standard can certainly be declared for grading the AS severity [6-9]. However, it is unequivocal and reflected in current guidelines that physiological assessment using TTE does provide the current gold standard in clinical practice for AS detection and grading AS severity, in preference to invasive assessment of transvalvular pressure gradient or planimetry in TEE $[1,5]$. Thus, conclusions of the exclusive evaluation of AS patients by Doppler echocardiography seem to be questionable due to the susceptibility to errors and consecutive shortcomings caused by methodological limitations, mathematical simplifications and inappropriate documentation $[10,11]$.

The present paper will address theoretical and practical issues of TTE documentation to satisfy the needs to analyze different AS scenarios due to various flow conditions and pressure gradients (Table 1). TTE measurements always interfere with the hemodynamic situation depending on factors like afterload, aortic annulus size, pressure recovery. The necessity to characterize different AS scenarios has led to the classification according to normal or low flow conditions as well as high or low gradients [1, 5, 12].

\section{Appropriate parameters for assessing the AS severity in all AS patients according to recent guidelines}

\section{Peak jet velocity $\left(V_{\max } A S\right)$ and mean pressure gradient $\left(\Delta P_{\text {mean }} A S\right)$}

Antegrade systolic velocity across the narrowed aortic valve is measured using continuous-wave Doppler (CWD) ultrasound with a parallel intercept angle between the ultrasound beam and the direction of blood flow. Accurate recording of data involves the evaluation of all acoustic windows including the supra and right parasternal window for determining the highest velocities. $V_{\max } \mathrm{AS}$ is defined as the highest velocity signal obtained from any window after careful examination $[8,13]$. Even when the imaging quality is poor, $V_{\max } \mathrm{AS}$ and $\Delta P_{\text {mean }} \mathrm{AS}$ can successfully be determined by CWD in most patients. The outer edge of the spectral Doppler envelope is traced to provide the velocity-time integral
(VTI) for both $\Delta P_{\text {mean }} \mathrm{AS}$ and calculations with the continuity equation (Table 1 ).

In sinus rhythm averaging of $V_{\max } \mathrm{AS}$ and $\Delta P_{\text {mean }} \mathrm{AS}$ in several beats seems to be crucial because the CWD spectrum is influenced by breathin manoeuvres and deviation of optimal Doppler angulation. In regular heart rhythm practical considerations favour measurements of the highest velocity signals to avoid errors. Averaging of at least five consecutive beats is recommended in patients with arrhythmia characterizing the hemodynamic sequelae of AS with respect to mean cardiac output. However, to characterize a representative hemodynamic situation normal LV filling with normal LV output can be analyzed by measuring $V_{\text {max }} \mathrm{AS}$ and $\Delta P_{\text {mean }} \mathrm{AS}$ in the second RR interval of two consecutive long RR intervals. Thus, representative sequences of beats have to be carefully selected during arrhythmias especially avoiding measurements after postextrasystolic beats. The shape of the CWD velocity curve is parabolic in valvular AS. In contrast, LVOT obstruction results in a late time-to-peak shape of the CWD velocity curve.

In general, $V_{\max } \mathrm{AS}$ and $\Delta P_{\text {mean }} \mathrm{AS}$ can be rated as reliable during normal flow conditions, normal LVSV and normal LV function. Most recent studies on transvascular aortic valve replacement have included patients with a $\Delta P_{\text {mean }} \mathrm{AS}>40 \mathrm{mmHg}$, which seems to be a hemodynamically unquestionable diagnosis for severe AS [14-16]. However, AS severity is hardly possible to assess by $V_{\max } \mathrm{AS}$ and $\Delta P_{\text {mean }} \mathrm{AS}$ alone, because increased transvalvular flow can also be observed in patients with moderate aortic stenosis and hyperdynamic LV function, e.g. in the presence of concomitant aortic regurgitation (AR) or increased cardiac output (e.g. anemia, hyperthyreosis, etc.). In general, underestimation of AS severity by determining $V_{\max } \mathrm{AS}$ and $\Delta P_{\text {mean }}$ AS may occur during low flow conditions, reduced LVSV and reduced LV function [17-20], overestimation during hyperdynamic circulatory states and by pressure recovery [21-24]. Pressure recovery describes the phenomenon of conversion of kinetic energy within the AS narrowing into pressure energy in the aortic root and the ascending aorta $[23,25]$. The maximum kinetic energy in AS is within the AS narrowing. The recovery of hydrostatic pressure in the aortic root occurs with decreasing velocities downstream the stenosis, because energy is neither created nor destroyed within the circulatory system. Thus, the net pressure gradient $\left(\Delta P_{\text {net }} \mathrm{AS}\right)$ corresponds to the peak-to-peak hydrostatic gradient between left ventricle and aortic root after recurrence of pressure recovery, but does not match with $\Delta P_{\text {mean }} \mathrm{AS}$. Pressure recovery is predominant, if transvalvular flow is less turbulent and the aortic root is small. In contrast, conversion of kinetic into thermal energy instead of pressure recovery is present in severe turbulent flow and dilated aortic roots. In conclusion, overestimation of $V_{\max } \mathrm{AS}$ and $\Delta P_{\text {mean }} \mathrm{AS}$ mainly occurs in AS patients with mild and 


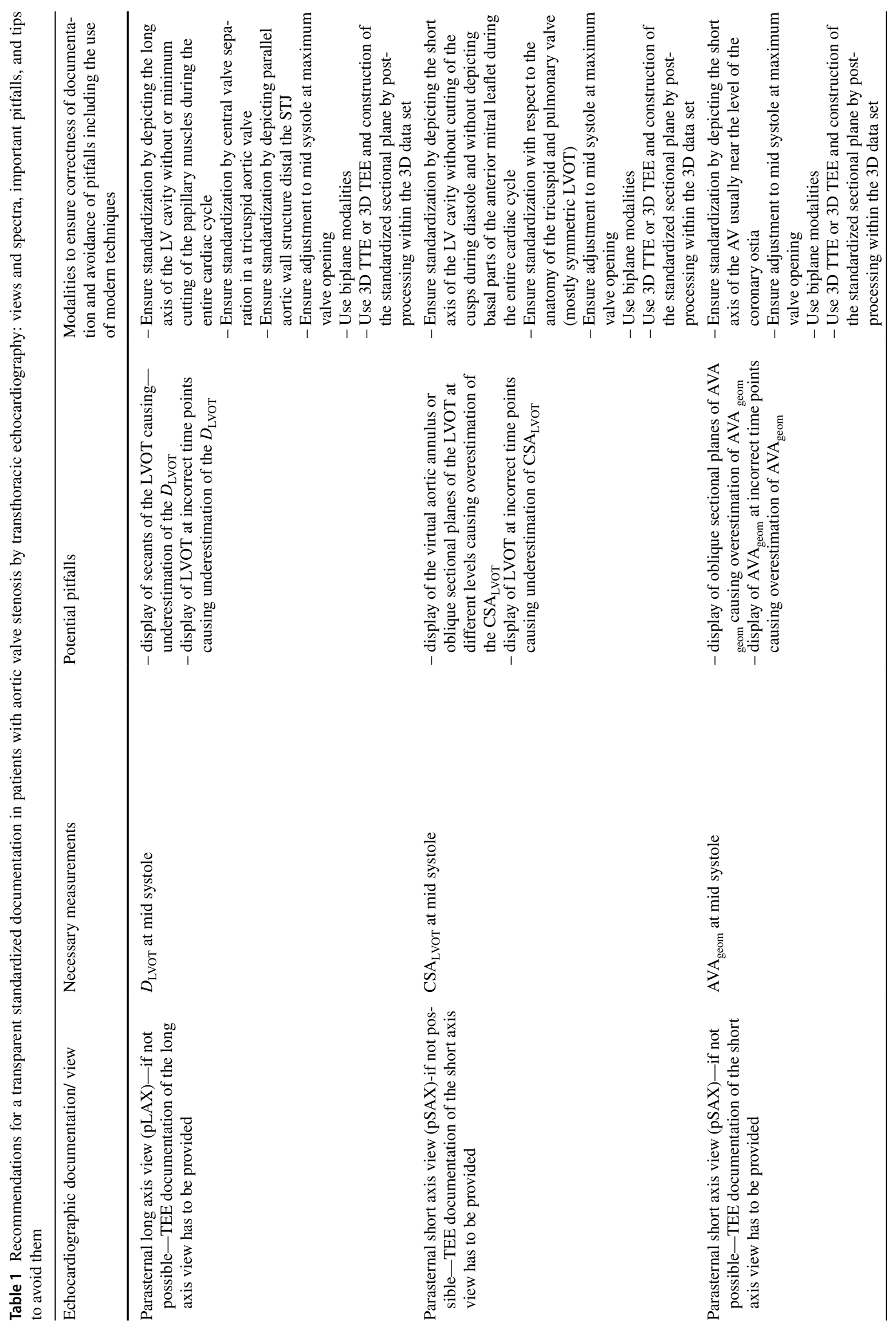




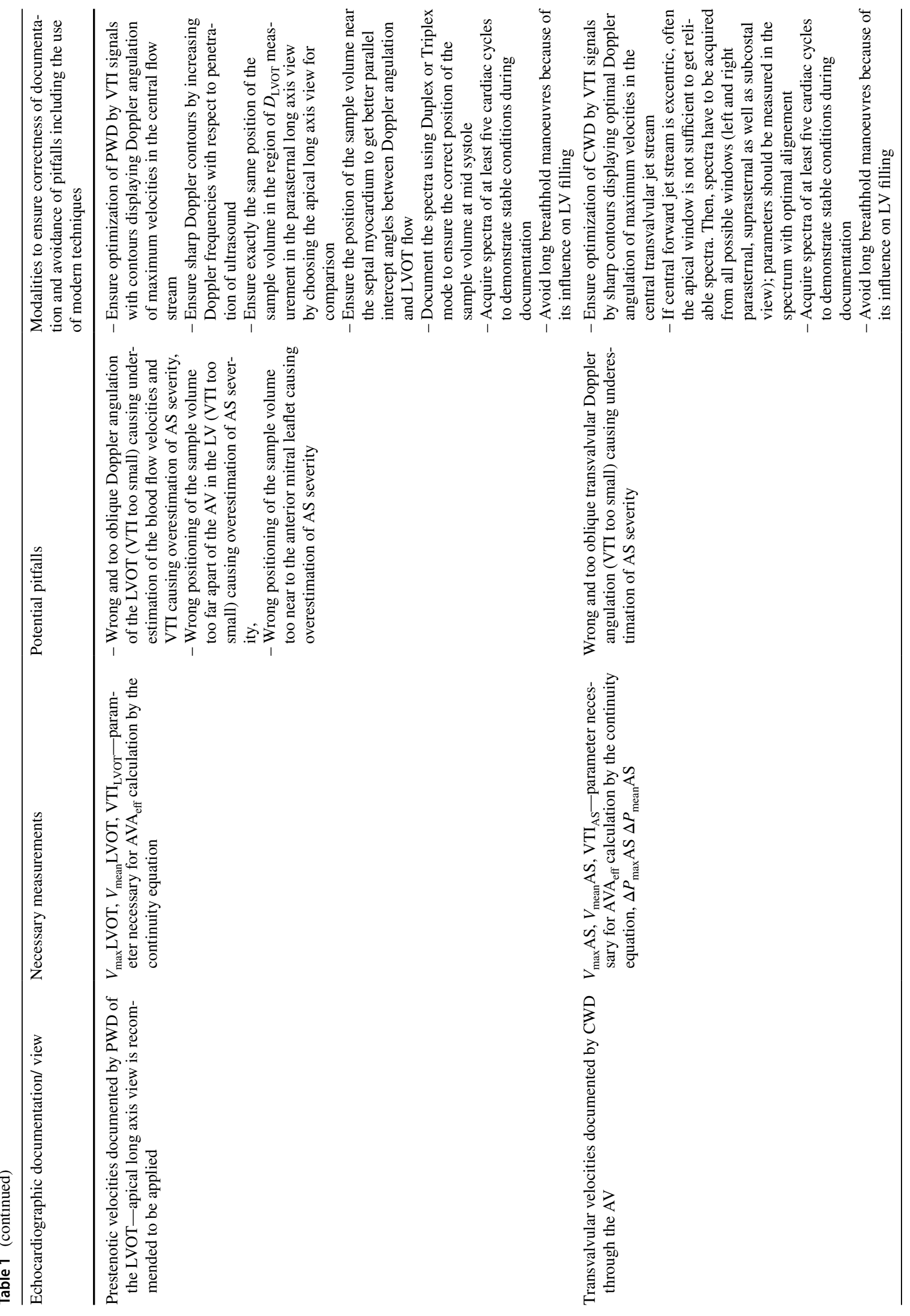


moderate AS and small aortic root size due to pressure recovery. Small dimensions can be assumed, if the diameter of sinutubular junction $\left(D_{\text {STJ }}\right)$ is less than $30 \mathrm{~mm}[23,25]$.

$\Delta P_{\text {mean }} \mathrm{AS}$ is estimated using information on transvalvular VTI by CWD. The peak gradient obtained from the peak velocity does not add additional information compared with $V_{\max } \mathrm{AS}$. The peak gradient $\left(\Delta P_{\max } \mathrm{AS}\right)$ is calculated using $V_{\max } \mathrm{AS}$ in the simplified Bernoulli equation. Because increased prestenotic flow $>1 \mathrm{~m} / \mathrm{s}$ and pressure recovery is not considered in the $\Delta P_{\max } \mathrm{AS}$ calculation, this parameter is highly prone to errors and should not be used for interpretations.

\section{Aortic valve area $\left(\mathrm{AVA}_{\text {eff }}\right)$}

$\mathrm{AVA}_{\text {eff }}$ is calculated using the continuity equation, which is based on the concept that stroke volume (SV) at the valve orifice level $\left(\mathrm{SV}_{\mathrm{AV}}\right)$ is equal to that at the LVOT $\left(\mathrm{SV}_{\mathrm{LVOT}}\right)$. Velocities and pressure gradients are flowdependent in rheology. For a specific orifice area, velocities and gradients increase with increasing transaortic flow rate and decrease with decreasing flow rate. The continuity equation $\left(\mathrm{SV}_{\mathrm{LVOT}}=\mathrm{SV}_{\mathrm{AV}}\right)$ requires the measurement of three parameters: $\mathrm{CSA}_{\mathrm{LVOT}}$ normally determined by using the LVOT diameter $\left(D_{\mathrm{LVOT}}\right)$ in the equation: $\mathrm{CSA}_{\mathrm{LVOT}}=\pi \times(D / 2)^{2}$, the prestenotic VTI in the LVOT $\left(\mathrm{VTI}_{\mathrm{LVOT}}\right)$ determined by pulsed wave Doppler (PWD), and the transvalvular VTI $\left(\mathrm{VTI}_{\mathrm{AS}}\right)$ determined by CWD. $\mathrm{AVA}_{\text {eff }}$ is calculated by the continuity equation $=\mathrm{AVA}_{\text {eff }}=\mathrm{CSA}_{\mathrm{LVOT}} \times \mathrm{VTI}_{\mathrm{LVOT}} / \mathrm{VTI}_{\mathrm{AV}}$.

Several limitations affect determination of $\mathrm{AVA}_{\text {eff }}$ using the continuity equation. Measurement of $D_{\mathrm{LVOT}}$ has to be accurately performed, because $1 \mathrm{~mm}$ difference can cause $10 \%$ variation of LVSV. Planimetry of $\mathrm{CSA}_{\mathrm{LVOT}}$ performed in 3D TTE and TTE data sets resulted in more accurate SV calculation than estimating $\mathrm{SV}$ using $D_{\mathrm{LVOT}}$ measured in the long axis view (Fig. 1) [26-31]. $\mathrm{CSA}_{\mathrm{LVOT}}$ can often be better determined by $3 \mathrm{D}$ transesophageal echocardiography (TEE) due to better spatial resolution in comparison to TTE (Table 1). $\mathrm{VTI}_{\mathrm{LVOT}}$ and $\mathrm{VTI}_{\mathrm{AS}}$ are mainly influenced by methodological factors including Doppler angulation, the position of the sample volume, Doppler frequency and many more (Table 1). Additionally, calculation of AVA eff $_{\text {pro- }}$ duces significant error by overestimating AS severity in the

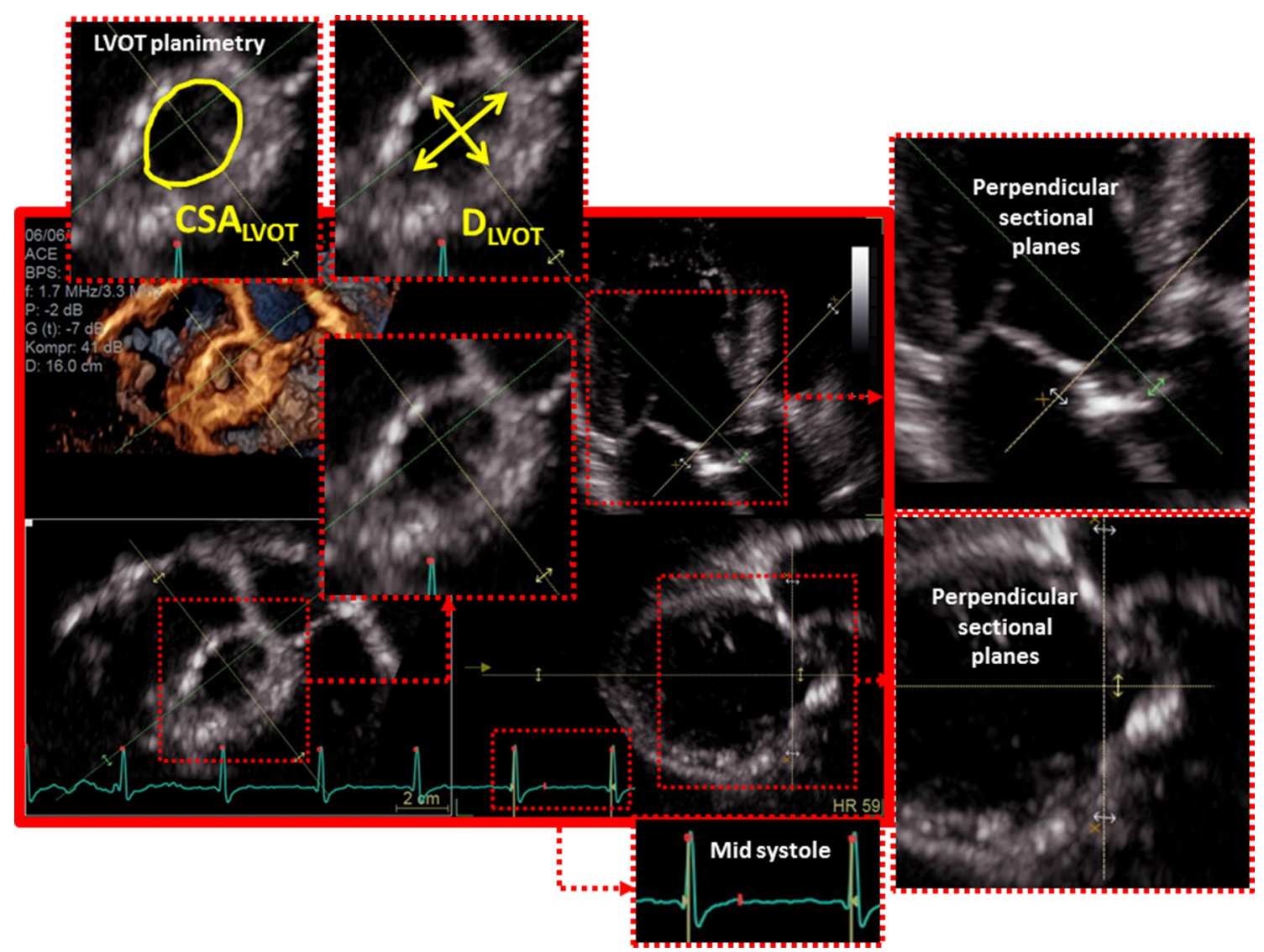

Fig. 1 Accurate-objective and transparent_LVOT planimetry and assessment of $\mathrm{D}_{\mathrm{LVOT}}$ performed in the correct sectional plane at the correct time point using using 3D TTE 
presence of increased LVOT velocities (increased $\mathrm{VTI}_{\mathrm{LVOT}}$ ) as well as pressure recovery.

$\mathrm{AVA}_{\text {eff }}$ calculated by continuity equation using $V_{\max } \mathrm{L}$ VOT and $V_{\max } \mathrm{AS}$, the ratio $V_{\max } \mathrm{LVOT} / V_{\max } \mathrm{AS}$ and $\mathrm{AVA} \mathrm{A}_{\text {geom }}$ are described as reasonable parameters if additional information is needed [2]. At least $\mathrm{AVA}_{\text {geom }}$-if planimetry can be correctly performed - should be discussed as a primary parameter for the assessment of AS severity (Figs. 2, 3, 4).

\section{Cardiac alterations for assessing hemodynamic relevance of AS}

The assessment of $V_{\max } \mathrm{AS}, \Delta P_{\text {mean }} \mathrm{AS}$, and $\mathrm{AVA}_{\text {eff }}$ recommended as the primary echocardiographic parameters for the evaluation of AS severity is obviously limited by several methodological and hemodynamic factors leading to incongruencies in the characterization of AS severity in clinical routine. Thus, it might be relevant to look for secondary cardiac alterations typically caused by severe AS like left ventricular hypertrophy (LVH), diastolic dysfunction and pulmonary hypertension $(\mathrm{PH})$. These signs underline the severity and are associated with a poor prognosis in AS patients [32-36]. Progressive narrowing of the aortic valve (AV) will lead to concentric LVH, which can be described by increased relative wall thickness $($ RWT $>0.42)$ and increased left ventricular mass $\left(\mathrm{LVM}_{i} \geq 95 \mathrm{~g} / \mathrm{m}^{2}\right.$ for women and $\geq 115 \mathrm{~g} / \mathrm{m}^{2}$ for men). With increasing LVH the diastolic pressure-volume relationship increases leading to diastolic dysfunction and secondary $\mathrm{PH}$. $E / E^{\prime}$ is known as the surrogate parameter for LV enddiastolic pressure (LVEDP). $\mathrm{PH}$ can be detected by increased systolic pulmonary artery pressure (sPAP). Because severe AS is highly unlikely if secondary cardiac alterations are not present, the assessment of RWT, $E / E^{\prime}$ and sPAP seems to be mandatory to support the diagnosis of severe AS. Furthermore, these parameters are independent of pressure and/or flow conditions.

Valvulo-arterial impedance (Zva) represents a marker of reduced arterial compliance characterizing excessive LV hemodynamic load. Thus, Zva describes hemodynamics and left ventricular dysfunction in severe AS patients [37, 38]. Zva is calculated according to the following equation: $\mathrm{Zva}=\left(P_{\text {sys }}+\Delta P_{\text {mean }} \mathrm{AS}\right) / \mathrm{SVI}$ where $P_{\text {sys }}$ is systolic arterial pressure, $\Delta P_{\text {mean }} \mathrm{AS}$ the mean transvalvular gradient, and

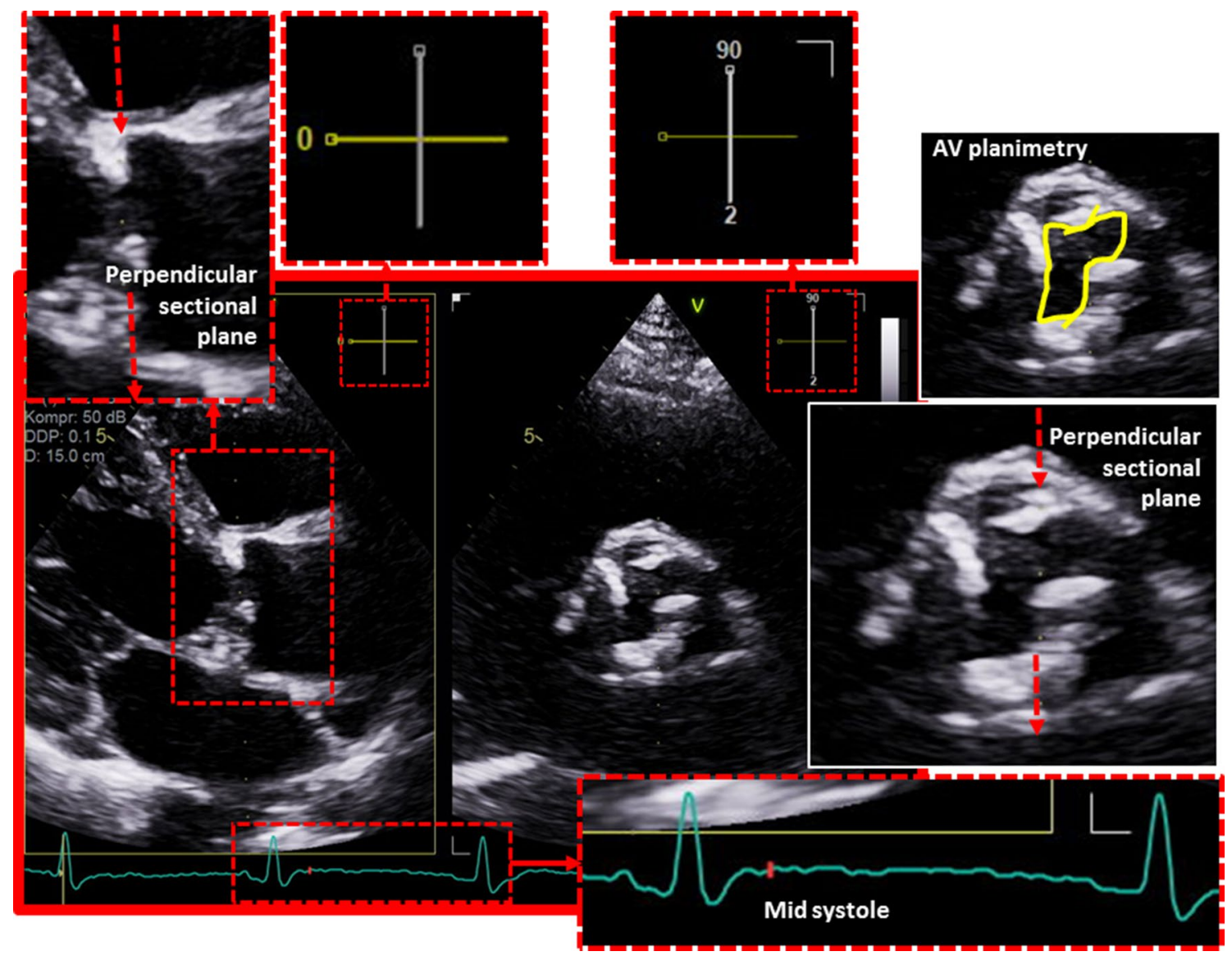

Fig. 2 Accurate—objective and transparent—AV planimetry of a bicuspid AV in mild AS performed in the correct sectional plane at the correct time point using using biplane 2D TTE 


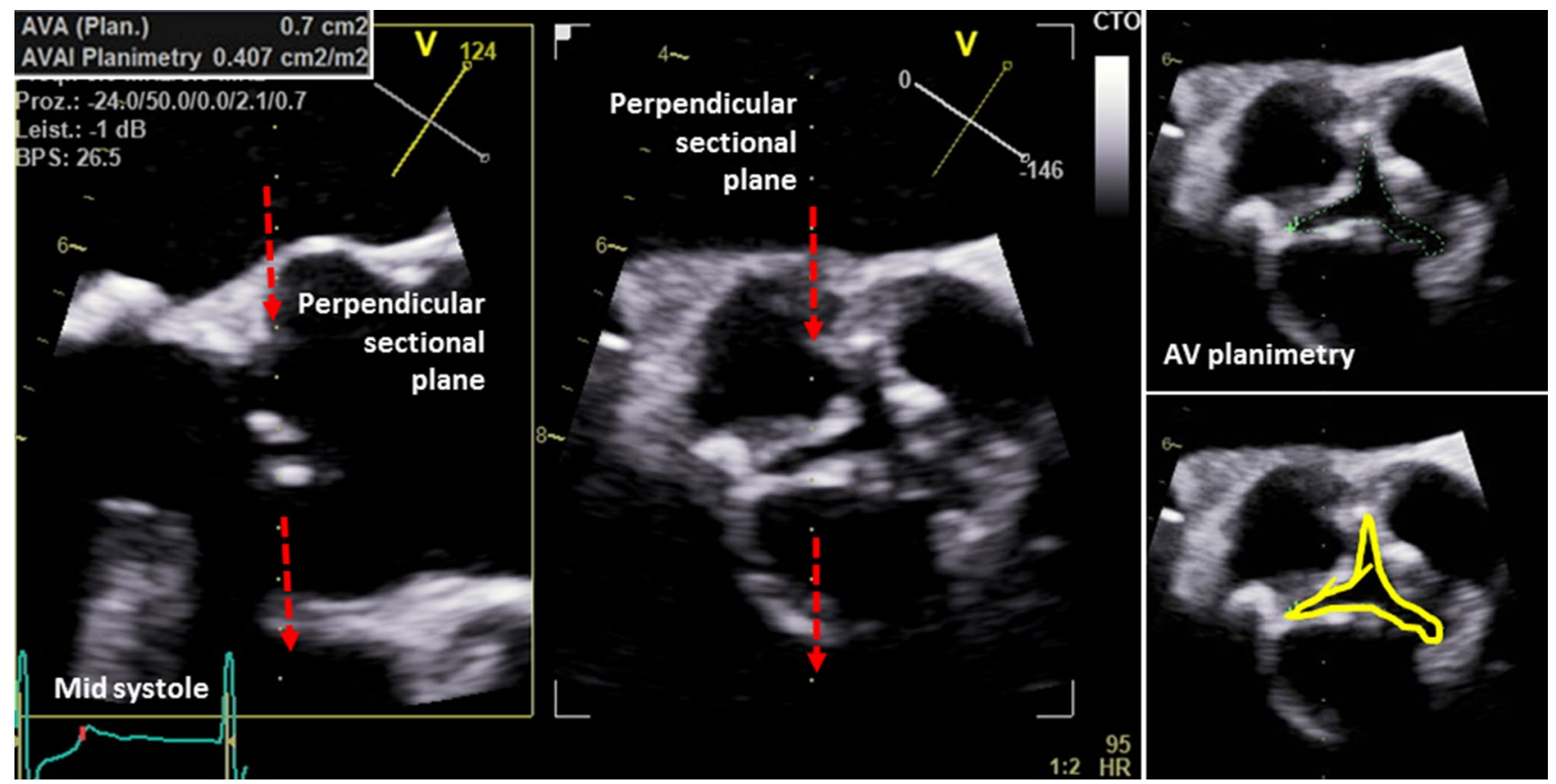

Fig. 3 Accurate-objective and transparent-AV planimetry of a tricuspid AV in severe AS performed in the correct sectional plane at the correct time point using using biplane 2D TEE

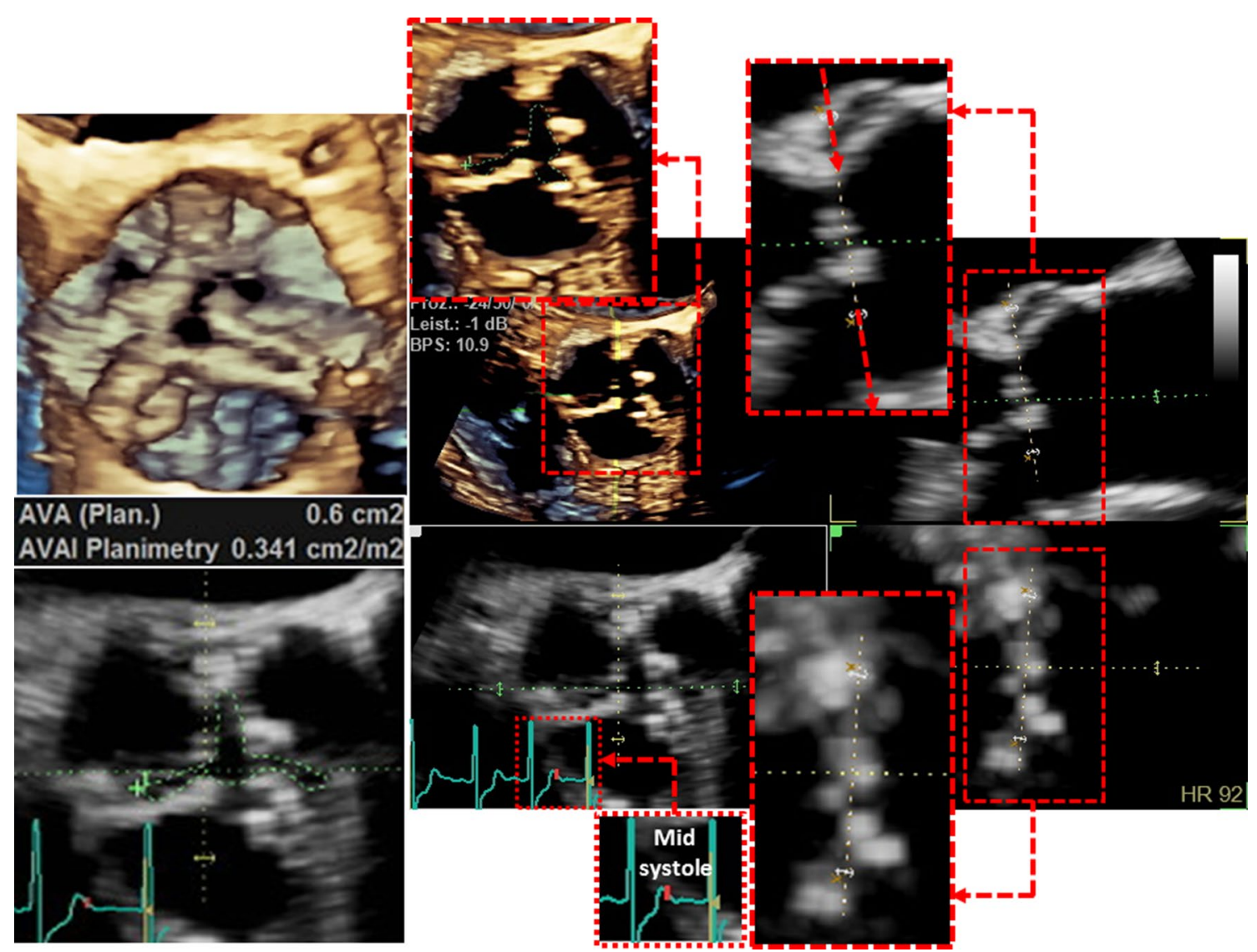

Fig. 4 Accurate-objective and transparent-AV planimetry of a tricuspid AV in severe AS performed in the correct sectional plane at the correct time point using using 3D TEE 
SVI the stroke volume index (SVI $=$ SV/BSA) where BSA is body surface area. Reduced arterial compliance is a frequent finding in AS patients and independently contributes to increased afterload. Increased Zva $>3.5$ successfully identifies patients with a poor outcome. Therefore, Zva might improve risk stratification and clinical decision making in AS patients. However, the variability of Zva due to the flow dependency is predominant in low-flow than in normal or high-flow conditions.

Myocardial fibrosis in AS patients can be described by the reduction of mitral annular plane systolic excursion (MAPSE) even in the presence of normal LV ejection fraction (LVEF) [39-42]. MAPSE is measured by M-Mode through the septal mitral annulus in the apical 4-chamber view and serves as a surrogate parameter for myocardial fibrosis. MAPSE $<5 \mathrm{~mm}$ indicates AS patients with severe fibrosis. In patients with low-gradient AS MAPSE $<9 \mathrm{~mm}$ is able to distinguish between moderate and severe AS [42].

\section{Echocardiographic parameters for assessment of prognosis in AS patients}

Prognosis of AS is strongly associated with the symptoms like angina, syncope and LV failure [42-46]. When facing patients with AS and symptoms it is often a challenge to judge whether the symptoms are really caused by the AS or by other reasons. On the other hand, some patients may be subjectively asymptomatic due to a reduced stress level in their daily life and would develop symptoms under exercise. Thus, it seems to be judicious to focus on prognostic relevant echocardiographic parameters in AS patients [42, 44-47].

Even in patients with mild AS with $V_{\max } \mathrm{AS}<3 \mathrm{~m} / \mathrm{s}$ and no $\mathrm{AV}$ calcification outcome is worse than in controls mainly due to ongoing adherence of the cusps. Rapid progression of aortic jet velocities can be detected by closer follow-ups and is accepted as a marker for high risk patients [35]. Cardiac and non-cardiac mortality is significantly increased in patients with moderate to severe AS with $V_{\max }$ AS between $3 \mathrm{~m} / \mathrm{s}$ and $5.5 \mathrm{~m} / \mathrm{s}$ in comparison to controls and mild AS patients $[12,35,44,47-51]$. However, it is necessary to correlate gradients with flow conditions and LV contractility, because $V_{\text {max }} \mathrm{AS}$ and $\Delta P_{\text {mean }} \mathrm{AS}$ are related to SV and LVEF. AS patients with normal LVEF are recently divided into normal flow (NF) and low flow (LF) conditions defined by the cut-off value of $35 \mathrm{ml} / \mathrm{m}^{2}$ for indexed SV and divided into normal or high gradient (HG) and low gradient (LG) conditions by the cut-off value of $40 \mathrm{mmHg}$ for $\Delta P_{\text {mean }} \mathrm{AS}$. In AS with normal LVEF the LF-LG AS patients have the worst prognosis, followed by comparable prognoses in LF-HG and NF-HG AS patients and NF-LG AS patients indicating the best prognostic value [11-13, 52, 53]. The definition of flow conditions in AS patients by indexed forward LVSV in the current guidelines $[1,5,12]$ can be scrutinized because a parameter describing a volume cannot exactly describe flow conditions, which corespond to volume per time unit. Transvalvular velocities and pressure gradients are influenced by the quantity of LVSV. Thus, increased forward LVSV might be oserved in AS patients with normal LVEF and bradycardia, in AS patients with relevant AR depending on the degree of regurgitation, and in patients with hyperdynamic states. Decreased forward forward LVSV might be present due to multiple factors like concentric LV remodeling with decreased LV cavity size, elevated arterial impedance, increased heart rate and small body height. A cardiac output in AS patients with normal LVEF and low heart rate will result in a higher LVSV with higher transvalvular velocities and pressure gradients than the same cardiac output in AS patients with normal LVEF and fast heart rate. Thus, flow conditions, which are defined by the indexed forward LVSV, describe the transvalvular flow per every particular ejection period, but not the flow conditions through the AV during a predefined time interval like e.g. cardiac output. This discrepancy between a volume and a flow parameter might presumably explain the relatively high number of patients with normal LVEF and severe LG AS in recent trials and registries [14-16, 54, 55].

With respect to the prognostic differences of AS subtypes [12, 52, 56, 57] it is further necessary to determine values indicating LV function including LVSV, LVEF and global longitudinal strain (GLS), respectively. LVSV can be determined by $\mathrm{SV}_{\mathrm{LVOT}}$ as the effective $\mathrm{SV}\left(\mathrm{SV}_{\text {eff }}\right)$ if no $\mathrm{AR}$ is present and if LVOT flow is not overestimated by hyperdynamic circulatory state or narrowing of the LVOT. Alternatively, $\mathrm{SV}_{\text {eff }}$ can be determined performing Doppler measurements at the right ventricular outflow tract, if no relevant pulmonary regurgitation is present. LV planimetrymostly performed by biplane Simpson`s method—is only reliable for determination of $\mathrm{SV}_{\text {eff }}$, if no mitral regurgitation (MR) and AR is present. In the presence of MR and/or AR LVSV determined by planimetry $\left(\mathrm{SV}_{\text {plan }}\right)$ represents $\mathrm{SVtot}$. In the presence of mixed aortic valve disease (MAVD) - the combination of AS and AR-without MR forward LVSV as well as $\mathrm{SV}_{\text {plan }}$ represents $\mathrm{SV}$ tot. Finally, $\mathrm{SV}_{\text {plan }}$ always represents $\mathrm{SV}_{\text {tot }}$ in the presence of MR and/or AR. Forward LVSV has generally be interpreted with regard to the regurgitant volumes (RV) of concomitant AR and MR (Fig. 5). Flow conditions and $\mathrm{SV}_{\text {eff }}$ can also be estimated by $3 \mathrm{D}$ TTE by volumetric evaluation of both ventricles. $\mathrm{LV}$ volume and LVEF measurements by 2D-planimetry or 3D-volumetry are more prone to errors, if the $\mathrm{LV}$ cavity becomes smaller. Thus, distinct LV endocardial contour detection is mandatory for reliable results. Different outcome of AS patients with comparable LVEF values is attributed to different degrees of LV fibrosis [42, 50, 53, 58]. Reduction of mitral ring displacement and MAPSE showed a strong correlation 


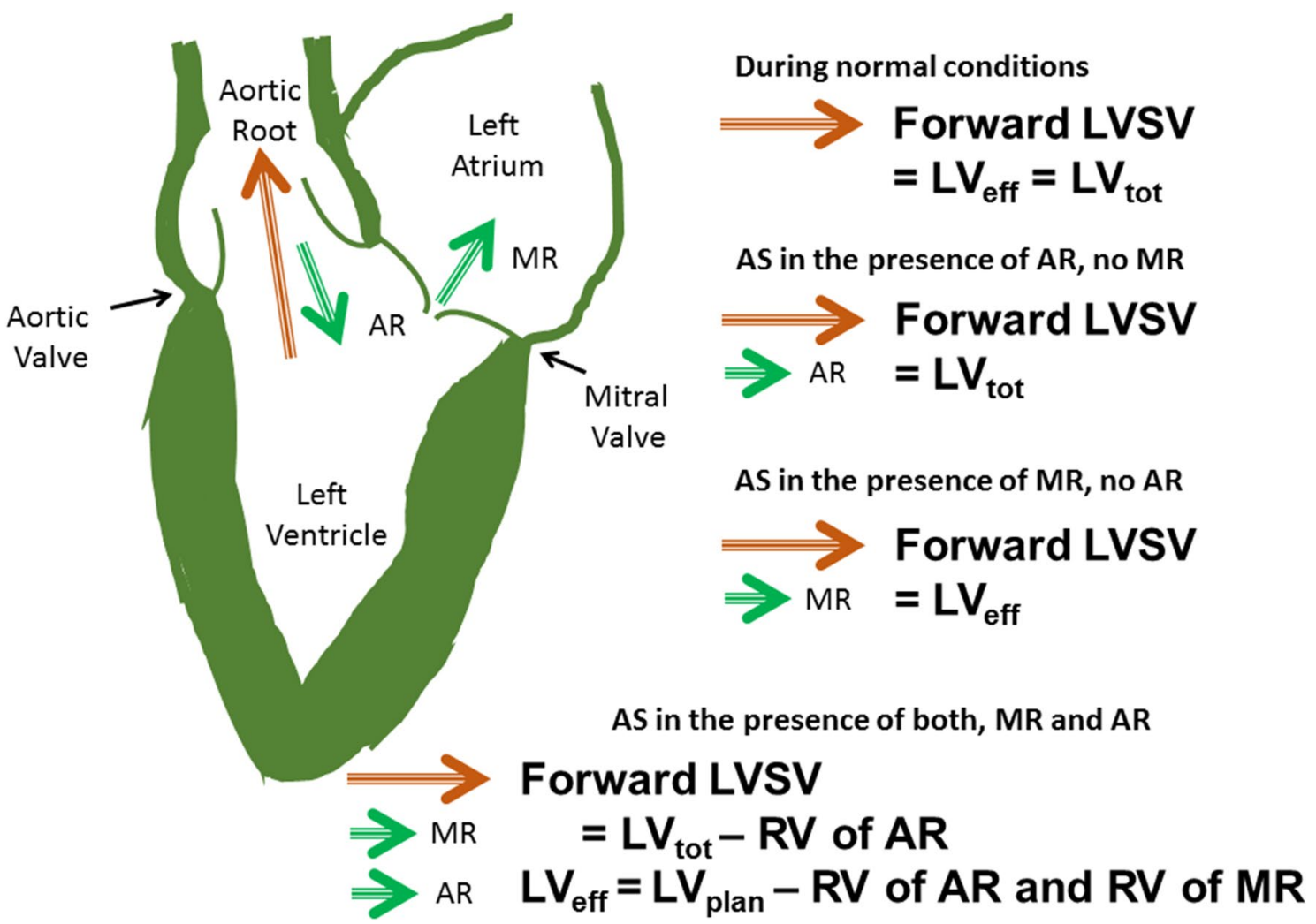

Fig. 5 Illustration of different compounds of forward LVSV during normal condition, in isolated AS, in MAVD in the absence or presence of MR

to the degree of myocardial fibrosis [39-42]. Whereas MAPSE might be deemed to be only a surrogate parameter for myocardial fibrosis, GLS seems to be a more sensitive parameter for detecting subclinical myocardial dysfunction as a prognostic marker in severe AS patients with preserved LVEF than the LVEF or MAPSE [42, 59]. This was especially shown in LF-LG AS patients [2]. GLS values derived by 3D TTE were shown to be more robust than GLS values derived by 2D TTE. However, speckle tracking by 2D TTE has a better temporal and spatial resolution than voxel tracking by 3D TTE. Recently, it could be shown that 2D GLS has strong predictive value for prognosis. A meta-analysis of ten studies with severe AS patients with preserved LVEF demonstrates reduced survival predicted by a cut-off value of GLS of $-14.7 \%$ [60].

\section{Practical considerations about image acquisition and data analysis to ensure diagnosis of severe AS}

The image documentation of a comprehensive TTE and TEE investigation should be standardized including image optimization, complete including display details presented with current technologies and transparent to be objectively controllable by supervisors.

Beside the standardized TTE documentation described in several recommendations special attention is commanded determining RWT, $D_{\mathrm{LVOT}}$, $\mathrm{CSA}_{\mathrm{LVOT}}$, the prestenotic mean and maximum velocities ( $V_{\text {mean }}$ LVOT, $V_{\text {max }}$ LVOT), VTI $_{\text {LVOT }}$, $V_{\text {mean }} \mathrm{AS}, V_{\max } \mathrm{AS}, \mathrm{VTI}_{\mathrm{AS}}, \mathrm{LVEF}, D_{\mathrm{STJ}}, E / E^{\prime}$ sPAP and $\mathrm{AVA}_{\text {geom }}$ by planimetry. The reliability of these parameters is important for correct calculation of $\mathrm{SV}_{\mathrm{LVOT}}$ and indexed $\mathrm{SV}_{\mathrm{LVOT}}, \mathrm{CSA}_{\mathrm{LVOT}}, \mathrm{AVA}_{\text {eff }}$ and $\Delta P_{\text {mean }} \mathrm{AS}$, and $\Delta P_{\max } \mathrm{AS}$ as well as conclusive interpretation of the data.

The risk of underestimation $D_{\mathrm{LVOT}}$ with the consequence of calculation $\mathrm{CSA}_{\mathrm{LVOT}}$ too small can be minimized by measurements in data sets of parasternal biplane image acquisition of the LVOT or in multidimensional 3D data sets of the LVOT and the aortic root. Using these modern approaches correct $D_{\mathrm{LVOT}}$ assessment and/or accurate planimetry of $\mathrm{CSA}_{\mathrm{LVOT}}$ is possible within the correct sectional plane and at the corresponding mid systolic time point of the cardiac cycle (Fig. 1). The same options exist for the assessment of $D_{\mathrm{STJ}}$, and planimetry of the cross sectional area of the aorta $\left(\mathrm{CSA}_{\text {Aorta }}\right)$ determined at the level of sinutubular junction (STJ). It is mandatory to assess distance measurements of 
$D_{\mathrm{LVOT}}$ and $D_{\mathrm{STJ}}$ and planimetry of $\mathrm{CSA}_{\mathrm{LVOT}}$ and $\mathrm{CSA}_{\text {Aorta }}$ at maximum values during mid systole.

The position of the sample volume in the LVOT has to be accurately adjusted at the same position and time point of the cardiac cycle where $D_{\mathrm{LVOT}}$ and $\mathrm{CSA}_{\mathrm{LVOT}}$ are measured. Minimal variations of the position of the sample volume cause significant alterations of the $\mathrm{VTI}_{\mathrm{LVOT}}$. Depending on the LVOT size and the intercept angle between the ultrasound beam and the direction of LVOT blood flow it is important to position the sample volume near the septal wall to optimize Doppler angulation (Fig. 6). In general, the apical long axis view enables a better control for checking the correct position of the sample volume at the region of $D_{\text {LVOT }}$ measurement (in contrast to the five-chamber view, in which a visual control is not possible). Furthermore, acquisition of the Doppler spectra using the duplex or triplex mode enables to check, whether the sample volume position is at the correct position at mid systole or not.

Inadequate assessment of CWD spectra of the transvalvular flow occurs, if the direction of ultrasound beam is not in line with the direction of the central AS jet stream. Thus, acquisition of CWD spectra derived from the suprasternal and right parasternal acoustic window are necessary, if Doppler angulation is obviously bad using the apical approach.

Methodologically, PWD and CWD spectra should be acquired during the same breathing manoeuvres and at the same heart rate to exclude different filling characteristics of the left ventricle influencing both spectra.

LVEF and left ventricular volumes can conventionally be estimated by planimetry of the two- and four-chamber view using the Simpson's method. $\mathrm{SV}_{\mathrm{LVOT}}$ measured by planimetry can only be reliably determined if endocardial contours are correct. Automatic analysis of LVEF often delineate the inner trabecula as the endocardium resulting in too small LV volumes despite correct LVEF. Thus, endocardial contours should be manually corrected. LV contrast imaging is helpful to label the correct endocardial surfaces. It is obvious that triplane or multidimensional data sets can improve LVSV measurements in the presence of missing LV cube geometry and adequate data sets. Volume measurement of the left and right ventricle by 3D TTE enables $\mathrm{SV}_{\text {eff }}$ determination, if no relevant valve regurgitations are present. In

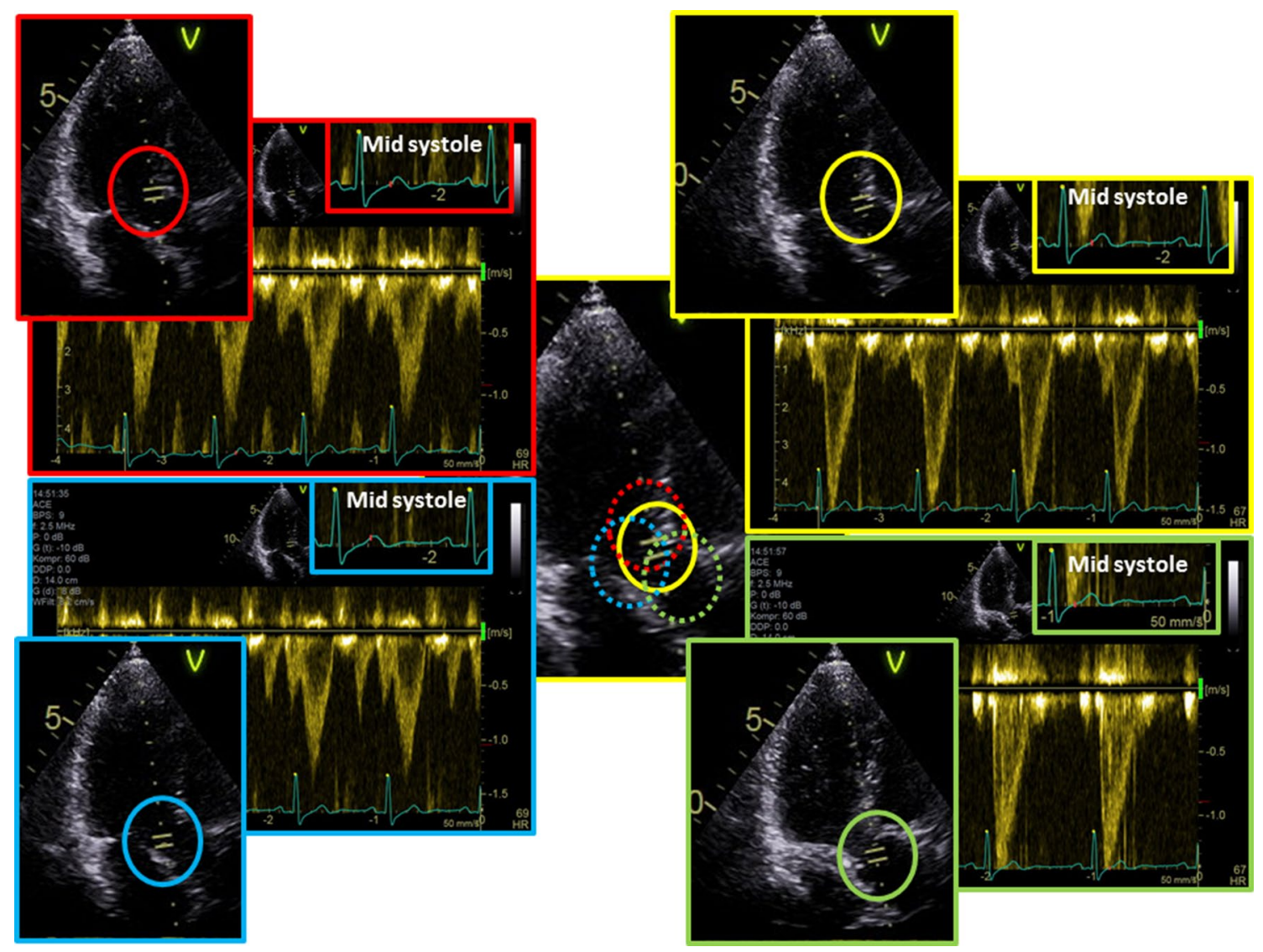

Fig. 6 Illustration of the effect of PWD sample volume position on LVOT spectrum in a normal AV. The yellow circle represents the correct position. The red circle is too far away from the aortic annulus. The blue circle is too near to the anterior mitral leaflet. The green cir- cle is at the aortic annulus between the cusps. In normal AV PWD spectra of LVOT and AV are normally equal, because diameters are equal 


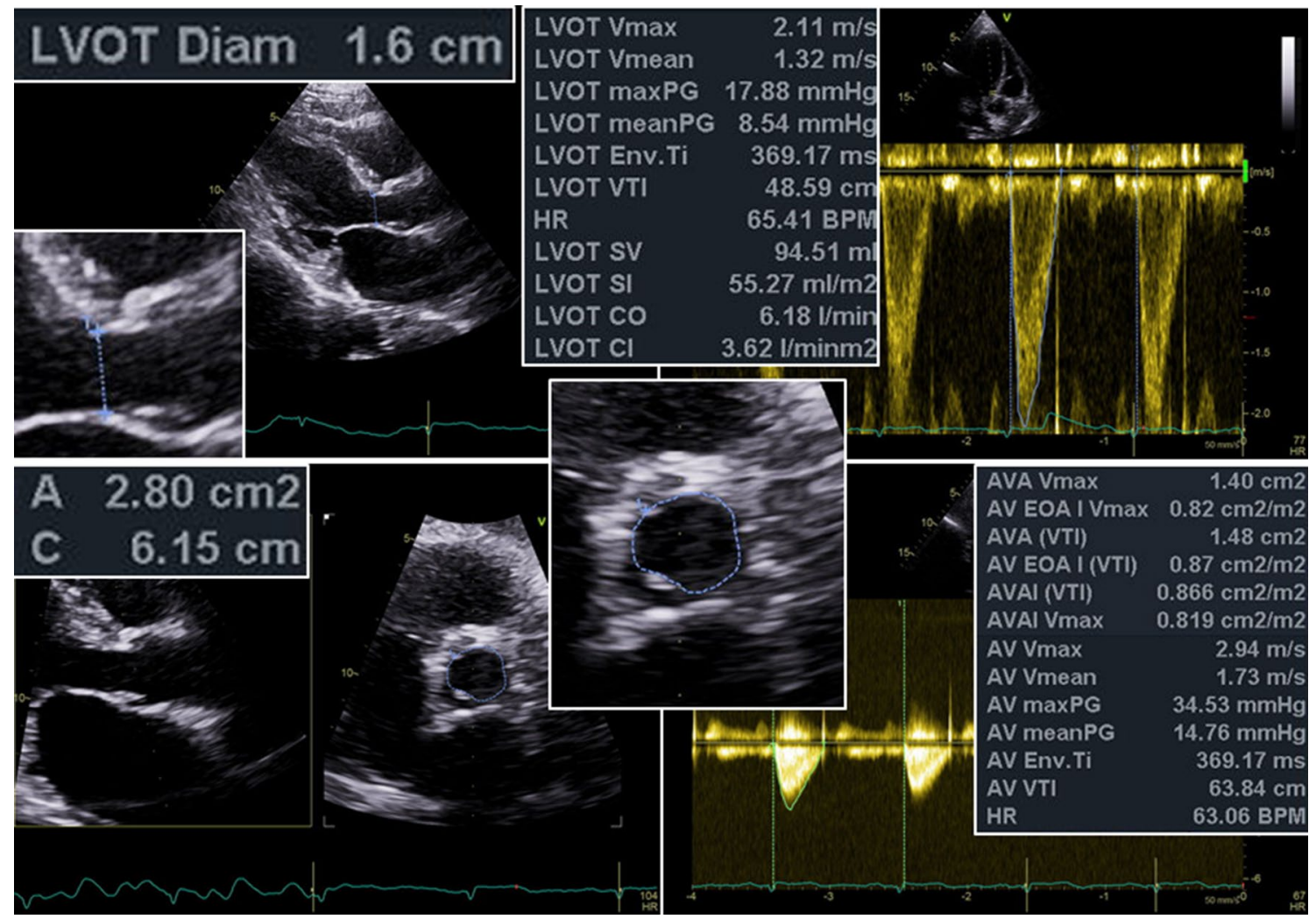

Fig. 7 Example of overestimation of AS severity in a small patient at hyperdynamic state $\left(V_{\max }\right.$ LVOT $\left.>2 \mathrm{~m} / \mathrm{s}\right)$ with small LVOT and aortic root dimensions $\left(D_{\mathrm{LVOT}}-16 \mathrm{~mm}\right)$ to document the effects of

the presence of aortic and mitral regurgitations LV planimetry and volumetry results in total stroke volume $\left(\mathrm{SV}_{\text {tot }}\right)$ assessment, which is important for quantitative assessment of regurgitant fraction in concomitant valvular regurgitations in AS patients [61-63]. However, it should be emphasized that high flow conditions will overestimate LVSV by Doppler measurements in comparison to LV planimetry (Fig. 7).

Because of the multiple errors in the assessment of the primary recommended target parameters to characterize AS severity, $V_{\max } \mathrm{AS}, \Delta P_{\text {mean }} \mathrm{AS}$ and $\mathrm{AVA}_{\text {eff }}$, the assessment of $\mathrm{AVA}_{\text {geom }}$ should be discussed. Beside the necessity of precise information regarding AV cuspidity, AV commissural orientation, $\mathrm{AV}$ calcification and the proximity between aortic annulus and coronary ostia $[64,65]$ to choose the best treatment strategy $\mathrm{AVA}_{\text {geom }}$ determination by planimetry is helpful to exclude obvious inconclusive measurements of $\mathrm{AVA}_{\text {eff }}$ by continuity equation. However, prerequisite is the correct assessment of data sets for $\mathrm{AVA}_{\text {geom }}$ planimetry. Planimetry of $\mathrm{AVA}_{\text {geom }}$ seems to be underused mainly due to reduced image quality in TTE. Actually, biplane and 3D TTE or TEE provide better orientation for correctly adjusting sectional plane at mid systole for assessment of $\mathrm{AVA}_{\text {geom }}$ perpendicular to the central axis of transvalvular flow in AS patients (Figs. 2, 3, 4). However, AVA $_{\text {geom }}$ planimetry in increased prestenotic flow and pressure recovery. AVAeff is calculated with $1.5 \mathrm{~cm}^{2}$. In contrast, the correct-objective and transparent-AV planimetry results in an AVAgeom $=2.8 \mathrm{~cm}^{2}$

2D and 3D TTE and TEE is still limited by laws of physics. Ultrasound frequency influence penetration and axial spatial resolution, frame rate spatial and temporal resolution, line density lateral resolution, and post processing rendering of the image contours, and all these factors have impact on the sharpness of AV cusps edges. Modern echocardiographic techniques - especially 3D TEE — can help to ensure reliable measurements of $\mathrm{AVA}_{\text {geom }}$ with excellent results (Fig. 4).

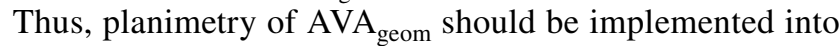
the group of primary key parameters for grading AS severity in all patients with AS. It is mandatory to perform planimetry of $\mathrm{AVA}_{\text {geom }}$ at mid systole at maximum opening of the AV documented by ECG.

\section{Considerations about the interpretation of the parameters $V_{\text {max }} A S, \Delta P_{\text {mean }} A S$, $A A_{\text {eff }}$ and AVA $_{\text {geom }}$ to avoid under- and overestimation of AS severity}

It is well known that alternatives to the three primary haemodynamic parameters recommended for clinical evaluation of AS severity are reasonable when additional 
information is needed in selected patients. Thus, there is no question to perform a TEE if PWD and CWD spectra by TTE are inadequate to diagnose severe AS and to quantify AS severity. The indication to perform a TEE in AS patients is generally accepted, if diagnosis cannot clearly be made by TTE. In this clinical scenario AVA $_{\text {geom }}$ by planimetry of TEE images is the major additional diagnostic parameter to quantify AS severity-mainly to avoid potential underestimation of AS severity by inadequate TTE images.

This approach raises questions about the general necessity of a TEE in AS patients to fix the correct diagnosis and about the necessary information in AS patients for correct decision making of potential treatment.

If $\Delta P_{\max } \mathrm{AS}$ is calculated by the simplified Bernoulli equation $\Delta P_{\max } \mathrm{AS}=4 \times V_{\max } \mathrm{AS}^{2}$, obviously the maximum instantaneous pressure gradients are calculated. It might be considered that this approach is only correct, if $V_{\max }$ LVOT is $<1 \mathrm{~m} / \mathrm{s}$ and $D_{\mathrm{STJ}}$ is $>30 \mathrm{~mm}$. In the presence of increased LVOT velocities and relevant pressure recovery due to small aortic root size overestimation of $\Delta P_{\text {mean }} \mathrm{AS}$ occurs. Especially in smaller patients (body height $<165 \mathrm{~cm}$ ) the $D_{\mathrm{LVOT}}$ is often $<18 \mathrm{~mm}$ and the $V_{\max }$ LVOT lies between 1.2 and $1.6 \mathrm{~m} / \mathrm{s}$. Thus, $\Delta P_{\text {mean }} \mathrm{AS}$ calculated by the simplified Bernoulli equation will be wrong. In addition, the constellation of small patients with a normal size of the aortic root $\left(D_{\text {STJ }}\right.$ is $>30 \mathrm{~mm}$ ) is rare causing additional miscalculation due to pressure recovery (Fig. 7).

If $V_{\max }$ LVOT is $>1 \mathrm{~m} / \mathrm{s}$ and $D_{\mathrm{STJ}}$ is $>30 \mathrm{~mm}$ (normal size of the aortic root), $\Delta P_{\text {mean }} \mathrm{AS}$ has to be calculated by the modified Bernoulli equation $\Delta P_{\text {mean }} \mathrm{AS}=4\left(V_{\text {mean }} \mathrm{AS}^{2}-V_{\text {mean }} \mathrm{LVOT}^{2}\right)$.

At least if $D_{\mathrm{STJ}}$ is $<30 \mathrm{~mm}, \Delta P_{\text {net }} \mathrm{AS}$ might be corrected according to the following equation:

$$
\begin{aligned}
\Delta P_{\text {net }} \mathrm{AS}= & \Delta P_{\max } \mathrm{AS}-\left\{\Delta P_{\max } \mathrm{AS} \times 2\right. \\
& \left.\times\left(\mathrm{AVA}_{\text {eff }} / \mathrm{CSA}_{\mathrm{Aorta}}\right) \times\left(1-\left[\mathrm{AVA}_{\text {eff }} / \mathrm{CSA}_{\text {Aorta }}\right]\right)\right\} .
\end{aligned}
$$

Thus, the corrected $\mathrm{AVA}_{\text {eff }}\left(\mathrm{AVA}_{\text {eff-corr }}\right)$ can be calculated by the equation:

$$
\mathrm{AVA}_{\text {eff - corr }}=\mathrm{AVA}_{\text {eff }} \times \mathrm{CSA}_{\text {Aorta }} /\left(\mathrm{CSA}_{\text {Aorta }}-\mathrm{AVA}_{\text {eff }}\right)
$$

For better understanding of these calculations and their importance for defining AS severity in the range of moderate to severe AS the following theoretical example of a presumably NFHG-AS in a patient with hyperdynamic flow conditions and small aortic root dimension is presented. The three primary haemodynamic parameters recommended for clinical evaluation of AS severity, $V_{\max } \mathrm{AS}$, $\Delta P_{\text {mean }} \mathrm{AS}$, and $\mathrm{AVA}_{\text {eff }}$, are assumed as follows for this hemodynamic scenario:

$$
\begin{aligned}
& V_{\max } \mathrm{LVOT}-2 \mathrm{~m} / \mathrm{s}, V_{\text {mean }} \mathrm{LVOT}-1.4 \mathrm{~m} / \mathrm{s}, \mathrm{VTI}_{\mathrm{LVOT}}-40 \mathrm{~cm}, \\
& V_{\max } A S-5.5 \mathrm{~m} / \mathrm{s}, V_{\text {mean }} \mathrm{AS}-4.0 \mathrm{~m} / \mathrm{s}, \mathrm{VTI}_{\mathrm{AS}}-130 \mathrm{~cm},
\end{aligned}
$$

$D_{\mathrm{LVOT}} 1.8 \mathrm{~cm}, D_{\mathrm{STJ}} 2.4 \mathrm{~cm}$

1. $\Delta P_{\max } \mathrm{AS}=4 \times V_{\max } \mathrm{AS}^{2}=4 \times 30.3=121 \mathrm{mmHg}$ (simplified Bernoulli equation using $V_{\max } \mathrm{AS}$ )

- $\mathrm{AVA}_{\text {eff }}=\mathrm{CSA}$ LVOT $\times V_{\text {max }} \mathrm{LVOT}$ $/ V_{\max } \mathrm{AV}=2.5 \times 2 / 5.5=0.9 \mathrm{~cm}^{2}$

2. $\Delta P_{\text {mean }} \mathrm{AS}=4 \times V_{\text {mean }} \mathrm{AS}^{2}=4 \times 16=64 \mathrm{mmHg}$ (simplified Bernoulli equation using VTI)

- $\mathrm{AVA}_{\text {eff }}=\mathrm{CSA} \mathrm{LVOT}_{\mathrm{T}} \times \mathrm{VTI}_{\mathrm{LVOT}}$ ' $\mathrm{VTI}_{\mathrm{AV}}=2.55 \times 40 / 130=0.8 \mathrm{~cm}^{2}$

3. $\Delta P_{\text {mean }} \mathrm{AS}=4 \quad\left(V_{\text {mean }} \mathrm{A} \mathrm{S}^{2}-V_{\text {mean }} \mathrm{L}-\right.$ $\left.\mathrm{VOT}^{2}\right)=4(16-2)=56 \mathrm{mmHg}$ (modified Bernoulli equation using VTI)

- $\mathrm{VTI}_{\mathrm{AV}}$, if $\Delta P_{\text {mean }} \mathrm{AS}$ is $56 \mathrm{mmHg}$, is about $115 \mathrm{~cm}$

- $\mathrm{AVA}_{\mathrm{eff}}=\mathrm{CSA} \mathrm{LVOT}_{\mathrm{T}} \times \mathrm{VTI}_{\mathrm{LVOT}} /$ $\mathrm{VTI}_{\mathrm{AV}}=2.55 \times 40 / 115=0.9 \mathrm{~cm}^{2}$

4. $\Delta P_{\text {net }} \mathrm{AS}=\Delta P_{\max } \mathrm{AS}-\left\{\Delta P_{\text {max }} \mathrm{AS} \times 2 \times\left(\mathrm{AVA}_{\mathrm{eff}}\right\}^{\prime}\right.$ $\left.\left.\mathrm{CSA}_{\text {Aorta }}\right) \times\left(1-\left[\mathrm{AVA}_{\text {eff }} / \mathrm{CSA}_{\text {Aorta }}\right]\right)\right\}$ (equation considering pressure recovery despite all limitations of this equation have to be considered)

$$
=121-\{121 \times 2 \times(0.9 / 4.50) \times(1-[0.9 / 4.50])\}
$$$$
=121-\{121 \times 2 \times 0.2 \times 0.8\}=121-38.7=
$$

$82 \mathrm{mmHg}$

- $\mathrm{AVA}_{\text {eff-corr }}=\mathrm{AVA}_{\text {eff }} \times \mathrm{CSA}_{\text {Aorta }} /\left(\mathrm{CSA}_{\text {Aorta }}-\mathrm{AVA}\right.$ eff $)=0.9 \times 4.5 /(4.5-0.9)=4.05 / 3.6=1.1 \mathrm{~cm}^{2}$

This example illustrates $\mathrm{AVA}_{\text {eff }}<1 \mathrm{~cm}^{2}$ in a high gradient AS patient by using the simplified Bernoulli equation classifying the patient as a severe AS patient. Considering pressure recovery reclassification into a moderate AS patient might be necessary due to a calculated $\mathrm{AVA}_{\text {eff }}>$ the cut-off value of $1 \mathrm{~cm}^{2}$ despite high values of $\Delta P_{\text {mean }} \mathrm{AS}$. It is known that contribution of pressure recovery is even more important if the AS is moderate, transvalvular flow is less turbulent and less increased and $D_{\mathrm{SVT}}$ is small ( $<30 \mathrm{~mm}$ ). In consequence, pressure recovery adjustment by $\mathrm{CSA}_{\text {Aorta }}$ assessment should generally be considered for accurate quantification of AS severity-especially in patients with an $\mathrm{AVA}_{\text {eff }}$ near below the cut-off value between 0.8 and $1.0 \mathrm{~cm}^{2}$. $\mathrm{CSA}_{\text {Aorta }}$ should be estimated at the level of the sinutubular junction [22]. Regarding the fact, that a moderate AS cannot be excluded by the diagnosis of a severe AS based on TTE analysis by $V_{\max } \mathrm{AS}, \Delta P_{\text {mean }} \mathrm{AS}$, and $\mathrm{AVA}_{\text {eff }}$ using the continuity equation, a TEE evaluation in AS patients possibly eligible for AS treatment can be regarded as necessary in nearly all patients-especially because AVA $_{\text {geom }}$ can be determined by 3D TEE in almost all patients. Pressure recovery is more predominant, the more laminar flow is present, and the smaller the aortic root. Thus, the exclusion of moderate AS is almost always necessary by TEE, if $\mathrm{AVA}_{\text {eff }}$ is in the ranges of $0.8 \mathrm{~cm}^{2}-1.0 \mathrm{~cm}^{2}$.

There are several additional reasons to establish TEE evaluation in the diagnostic procedure of AS patients if TTE 
investigation is not conclusive. Because the measurements of $\mathrm{LV}$ volumes and $\mathrm{LVEF}$, flow conditions, $\mathrm{CSA}_{\mathrm{LVOT}}, \mathrm{AVA}_{\text {geom }}$, $D_{\mathrm{STJ}}$ and dimensions of the proximal ascending aorta, the detection of cuspidity of the AV and of aortic plaque load, as well as the assessment of additional valvular heart diseases cannot be sufficiently assessed by TTE, a TEE examination seems to be reasonable in nearly all AS patients to clarify the diagnosis and guide decision making and adequate therapy.

Finally, the recommendation to define $1 \mathrm{~cm}^{2}$ as the cut-off value of $\mathrm{AVA}_{\text {eff }}$ for severe AS is not easily comprehensible in the literature, because prognosis in AS patients was evaluated using all three primary key parameters $V_{\max } \mathrm{AS}$, $\Delta P_{\text {mean }} \mathrm{AS}$ or $\mathrm{AVA}_{\text {eff }}$ with respect to different cut-off values $[2,12,27,35,41,48-51]$. However, it can be concluded from the results of recent trials that the recommended cut-off value of $\mathrm{AVA}_{\text {eff }}$ determined by echocardiography is wellfounded $[24,66]$.

\section{Summary and conclusion}

$V_{\text {max }} \mathrm{AS}, \Delta P_{\text {mean }} \mathrm{AS}$, and $\mathrm{AVA}_{\text {eff }}$ are accepted as the primary key parameters to quantify AS severity. Due to the fact that $\mathrm{AVA}_{\text {eff }}$ determination using the continuity equation is highly prone to errors-especially if the image quality in TTE is limited and the acquisition of reliable PWD and CWD spectra is questionable - this expert consensus document addresses the following considerations: (1) TEE should be discussed for reliable measurement of $\mathrm{AVA}_{\text {geom }}$ and of the aortic root dimensions at an early stage of the diagnostic procedure. (2) To avoid misinterpretation due to inconsistent results $\mathrm{CSA}_{\mathrm{LVOT}}$ and $\mathrm{D}_{\mathrm{LVOT}}$ should be assessed using biplane or 3D echocardiography. (3) Practical recommendations of the standardized TTE documentation should provide a verifiable TTE investigation for a transparent check by a supervisor. These recommendations focuss on the correct position of the PWD sample volume in the LVOT, which should be documented in cineloops of the spectra using duplex or triplex mode. The correct angulation of the transvalvular ultrasound beam of the CWD should also be accurately documented using duplex or triplex mode. LVSV has to be measured by Doppler echocardiography as well as by LV planimetry or LV volumetry to enable counterchecking of the LV stroke volumes. Depending on the presence of further valvular heart diseases $\mathrm{SV}_{\text {eff }}$ should be measured by Doppler echocardiography at the right ventricular outflow tract or by right ventricular volumetry using 3D echocardiography. LVSV and LVEF, MAPSE and GLS should be mandatory implemented into the analysis of AS patients to estimate prognosis of severe AS patients. (4) If the results of a TTE investigation are not conclusive, TEE-mainly 3D TEE - and/or cardiac magnetic resonance (CMR) and/ or cardiac computed tomography (CT) should be performed to determine $\mathrm{AVA}_{\text {geom }}$ and $\mathrm{AV}$ calcification. However, the assessment of the hemodynamic situation is still a TTE domaine in AS patients. TEE, CMR and CT predominantly flank the TTE results by accurate morphological assessment of cardiac and aortic structures.

Funding This research did not receive any specific grant from funding agencies in the public, commercial, or not-for-profit sectors.

\section{Compliance with ethical standards}

Conflict of interest None.

\section{Appendix: Conference discussion}

Prof. Dr. Hagendorff (Leipzig): Regarding two hot topics about echocardiography in AS patients at the 1. Mitteldeutscher Echokardiographie Kongress in Leipzig-“the damnation resulting from consequence of the continuity equation" and the debate "Pro and Con: The diagnostic analysis of AS patients is correctly performed in the current clinical practice"-we have an interesting communication. My first question is: When you look at the multiple errors of $\mathrm{AVA}_{\text {eff }}$ calculation, is there still any reason not to perform a planimetry of the LVOT instead of measuring $\mathrm{D}_{\mathrm{LVOT}}$ ?

Prof. Dr. Knebel (Berlin): 3D TTE and 3D TEE-and also cardiac MR and CT-have shown that the $\mathrm{CSA}_{\mathrm{LVOT}}$ is often not circular shaped. $D_{\mathrm{LVOT}}$ measurements in 2D TTE address to the smaller diameter of the ellipse causing an important underestimation of $\mathrm{CSA}_{\mathrm{LVOT}}$, which is more pronounced with increasing distance from the AV annulus level. $\mathrm{CSA}_{\mathrm{LVOT}}$ measurement in our days should be performed by 3D TEE, because direct planimetry of the individual $\mathrm{CSA}_{\mathrm{LVOT}}$ is more precise than calculation a circular $\mathrm{CSA}_{\mathrm{LVOT}}$ by a not representative $D_{\mathrm{LVOT}}$. If $D_{\mathrm{LVOT}}$ is still used, inner edge to inner edge measurements should be performed with greatest care and maximum accuracy at mid systole in a zoomed data set-preferentially at AV annulus level.

Prof. Dr. Hagendorff (Leipzig): Misinterpretation of $\mathrm{AVA}_{\text {eff }}$ calculated by the continuity equation obviously leads too often to diagnosis of severe AS because of underestimation of $\mathrm{CSA}_{\mathrm{LVOT}}$. How would you confirm the diagnosis of severe AS?

Dr. Stöbe (Leipzig): The main challenge-especially for trainees and younger colleagues - is to detect a possible misinterpretation. Thus, the parameters RWT, $E / E^{\prime}$ and sPAP should be correctly interpreted. Severe AS might be highly unlikely without the presence of $\mathrm{LVH}$, diastolic dysfunction including increased LVEDP and secondary PH. All of these secondary cardiac alterations represent pathophysiological 
adjustment mechanisms in severe AS. If there is a doubt to quantify the AS severity, the next attempt should be the direct planimetry of the AV orifice area-preferable by $3 \mathrm{D}$ TEE.

Prof. Dr. Hagendorff (Leipzig): Are there possible clinical parameters to confirm the diagnosis of severe AS in the echo lab?

PD Dr. Sinning (Hamburg): Low systolic blood pressure and decreased pulse pressure are normally regarded as clinical signs of severe AS. Thus, blood pressure measurement should be performed to support by physical examination the diagnosis of severe AS. However, hypertension sometimes exists in AS patients, because systemic hypertension is one risk factor for AS. In addition, it is known that transvalvular pressure gradient decreases at increased peripheral resistance causing potential underestimation of AS severity. Thus, simultaneous blood pressure measurements during TTE in AS patients should be performed. Clinical complaints and parameters per se should be analyzed with respect to a proven sequelae of the valvular heart disease. Unspecific complaints like disability and dizziness can be caused by many other factors than severe AS, e.g. by anemia, primary and secondary amyloidosis, chronic infections as well as malignomas. Thus, all differential diagnoses should be excluded before final decision making to therapeutically options-especially in borderline results by TTE and TEE investigations.

Prof. Dr. Hagendorff (Leipzig): To characterize the flow conditions in AS patients, which method is the best: $\mathrm{SV}_{\text {eff }}$ determination by planimetry/volumetry or by Doppler echocardiography using $D_{\mathrm{LVOT}}$ or the diameter of the right ventricular outflow tract?

PD Dr. Ewen (Homburg/Saar): LVSV determination of the left ventricular stroke volume is necessary to differentiate between normal $\left(\geq 35 \mathrm{ml} / \mathrm{m}^{2}\right)$ and reduced flow $\left(<35 \mathrm{ml} / \mathrm{m}^{2}\right)$ conditions indicating the transvalvular forward flow. LVSV can be determined via LV planimetry using the biplane Simpson method or by Doppler echocardiography using the equation: $\mathrm{LVSV}=0.785 \times D_{\mathrm{LVOT}} \times \mathrm{VTI}_{\mathrm{LVOT}}$. However, both methods theoretically (and if well performed also practically) only correspond, if no mitral and AR is present. LVSV is normally measured by Doppler echocardiography for characterization of flow characteristics, which is $\mathrm{SV}_{\text {eff }}$ in patients with isolated AS and $\mathrm{SV}_{\text {tot }}$ in patients with $\mathrm{AR}$ and no mitral regurgitation. Direct planimetry of LVOT by 3D echocardiography can avoid errors by underestimation $\mathrm{CSA}_{\mathrm{LVOT}}$ using $D_{\mathrm{LVOT}}$ for calculation of a circular CSA $\mathrm{LVOT}_{\mathrm{L}}$ by Doppler echocardiography. Taken together, both methods have their strengths and weaknesses; however, the stroke volume values obtained should differ $<10 \%$ between the two methods.

Prof. Dr. Hagendorff (Leipzig): Is the so-called "normal flow-low gradient AS with preserved or normal
LVEF" a true entity or is it an issue of misconception of measurements?

Dr. Helfen (Lünen): The "normal flow-low gradient AS with preserved or normal LVEF" is described in the literature as a true entity. However, in clinical practice it can be assumed that most of the AS patients described as having these cardiac characteristics are misclassified by measurement errors due to overestimation of AS severity determining $\mathrm{AVA}_{\text {eff }}$ by the continuity equation. The main sources of errors can be summarized: (1) the too small $D_{\mathrm{LVOT}}$ (2) the wrong position of the PWD sample volume too far away from the aortic anulus, and (3) the lack of considering pressure recovery in potential mild or moderate AS patients. Disconcordant results and the absence of secondary cardiac alterations should always cause hesitation to diagnose severe AS. The fact, that normal or high transvalvular gradients can be observed in the presence of very small LV cavities and LVSV in AS patients with normal LVEF, principally poses the question whether a severe AS is generally possible at normal flow-low gradient conditions in patients with preserved or normal LVEF or not.

Prof. Dr. Hagendorff (Leipzig): Do you think AVA $_{\text {geom }}$ should be established as a primary parameter to quantify AS severity?

PD Dr. Fehske (Köln): Planimetry of AV orifice area has been described very early already using 2D TTE. However, 2D TTE is generally not often used mainly due to reduced image quality. The better spatial resolution in TEE and the optimal adjustment of the sectional planes within 3D TEE data sets perpendicular to the forward jet stream of the $\mathrm{AV}$ orifice area at the correct mid systolic time point of the cardiac cycle techniques predisposes $\mathrm{AVA}_{\text {geom }}$ assessment to a primary parameter of quantifying AS severity. Thus, the answer is easy. It is simply yes.

Prof. Dr. Hagendorff (Leipzig): Do you think an additional AV regurgitation will influence the transvalvular velocities and causes misinterpretations of quantifying AS severity?

Dr. Knierim (Berlin): The combination of AS and AR also called MAVD is a challenge to quantify AS severity with respect to decision making process. Color jet area is generally not recommended for quantification AR severity and pressure halftime is not reliable in MAVD patients. Assessment of $\mathrm{SV}_{\text {eff }}$ and $\mathrm{SV}_{\text {tot }}$ by Doppler echocardiography or by volumetry of the ventricles seems to be the only reliable method to calculate regurgitant volume in MAVD. Of course, transvalvular AV velocities will increase with increasing AR severity. Thus, the overall AV velocity represents an easy assessable parameter that reflects both AS and AR. In asymptomatic patients with MAVD this parameter was predictor of event-free survival independent of the severity of AS and AR. A combination of moderate AS and moderate AR may be consistent with severe valve disease 
if the overall velocity is $>3.9 \mathrm{~m} / \mathrm{s}$. In addition, it needs to be mentioned that AR may interfere with adequate delivery of cardioplegia solution to the myocardium during surgical AV replacement (SAVR). Therefore, identification and grading of AR severity is very important in severe AS patients undergoing surgical AV therapy.

Prof. Dr. Hagendorff (Leipzig): With respect to pressure recovery should $\mathrm{AVA}_{\text {eff }}$ be corrected when quantifying AS severity? Do you think this approach needs to be considered in the next recommendations?

PD Dr. Fehske (Köln): The phenomenon of pressure recovery is well described and proven in the literature. Thus, AS severity can always be overestimated in moderate AS patients with small body size and small dimensions of the aortic root. Especially in these patients pressure recovery adjustment of $\mathrm{AVA}_{\text {eff }}$ should definitively be performed. The results of the SEAS substudy document that $47.5 \%$ of patients classified as having severe AS were reclassified to non-severe AS when pressure recovery was taken into account. This observation underlines the need for pressure recovery adjustment of $\mathrm{AVA}_{\text {eff }}$. Pointing to these basic methodological aspects, which have to be changed, and to finalize our discussion, do you think that severe AS is overdiagnosed in the era of TAVI?

Prof. Dr. Hagendorff (Leipzig): It can be assumed that inconsistent results in AS patients could be the reason for overdiagnosis of severe AS in the clinical scenario. However, this expert consensus document should not create the impression, that the main thrust seems to avoid overdiagnosis of severe AS. It is commonly and overall accepted to use the continuity equation for the calculation of $\mathrm{AVA}_{\text {eff }}$ as a primary clue for decision making in AS patients. The main problem in this context is the error-proneness of both parameters, $D_{\mathrm{LVOT}}$ and $\mathrm{VTI}_{\mathrm{LVOT}}$, with the risk of underestimation causing overestimation of AS severity in either instance. If we are working with the continuity equation and its limitations, why should not also we work with a second equation, which provides sensibility to scrutinize a potential wrong diagnosis. This seems to be the rationale to implement into diagnostic procedures the calculation of pressure recovery prior to decision making in AS patients and to check the diagnosis by planimetry of $\mathrm{AVA}_{\text {geom. }}$. In this expert consensus document Fig. 7 nicely demonstrate a 54\% underestimation of the correct valve orifice area by calculation $\mathrm{AVA}_{\text {eff }}$ using the continuity equation $\left(\mathrm{AVA}_{\text {eff }}=1.5 \mathrm{~cm}^{2}\right.$; $\mathrm{AVA}_{\text {geom }}=2.8 \mathrm{~cm}^{2}$ ). This is also illustrated by the object lesson in the calculation of a fictional example, which should not be confusing or misleading, but rather addressing the basic problems of the interpretation of calculated values. Thus, the main issue for all of us should be an improvement of echocardiographic education to provide better understanding of echocardiographic results and to explain hemodynamic characteristics in patients with heart valve disease to avoid misinterpretation of echocardiographic findings. One valid precaution against overdiagnosis of severe AS could be the prerequisite of a 3D TEE investigation prior making a diagnosis of severe AS anyway. Despite several recommendations and guidelines there are some issues which should be reconsidered in the literature in future. (1) We should focus again more on methodological details and practical tips performing TTE and TEE investigations in AS patients as described in the present paper (2) we should use automated algorithms implemented in the measuring programs of the ultrasound systems for the correct calculation of $\mathrm{AVA}_{\text {eff }}$ with respect to defined different hemodynamic conditions and to the size of anatomical cardiac structures (3) we should answer the question why the cut-off value for severe AS was altered from $<0.8$ to $<1.0 \mathrm{~cm}^{2}$ in the last recommendations and if this approach was correct and (4) we should reevaluate AS prognosis in AS subgroups because most prognostic data of AS patients are validated for $\mathrm{AVA}_{\mathrm{eff}}<0.8 \mathrm{~cm}^{2}$. Thank you all for the interesting discussion.

\section{References}

1. Baumgartner H, Falk V, Bax JJ, De Bonis M, Hamm C, Holm PJ, Iung B, Lancellotti P, Lansac E, Rodriguez Muñoz D, Rosenhek R, Sjögren J, Tornos Mas P, Vahanian A, Walther T, Wendler O, Windecker S, Zamorano JL (2017) 2017 ESC/EACTS Guidelines for the management of valvular heart disease. Eur Heart J 38:2739-2791. https://doi.org/10.1093/eurheartj/ehx391

2. Baumgartner HC, Hung JC-C, Bermejo J, Chambers JB, Edvardsen T, Goldstein S, Lancellotti P, LeFevre M, Miller F, Otto CM (2017) Recommendations on the echocardiographic assessment of aortic valve stenosis: a focused update from the European association of cardiovascular imaging and the American society of echocardiography. Eur Heart J Cardiovasc Imaging 18(3):254-275. https://doi.org/10.1093/ehjci/jew335

3. Lang RM, Badano LP, Mor-Avi V, Afilalo J, Armstrong A, Ernande L, Flachskampf FA, Foster E, Goldstein SA, Kuznetsova T, Lancellotti P, Muraru D, Picard MH, Rietzschel ER, Rudski L, Spencer KT, Tsang W, Voigt JU (2015) Recommendations for cardiac chamber quantification by echocardiography in adults: an update from the American society of echocardiography and the European association of cardiovascular imaging. Eur Heart J Cardiovasc Imaging 16:233-270. https://doi.org/10.1016/j. echo.2014.10.003

4. Mitchell C, Rahko PS, Blauwet LA, Canaday B, Finstuen JA, Foster MC, Horton K, Ogunyankin KO, Palma RA, Velazquez EJ (2019) Guidelines for performing a comprehensive transthoracic echocardiographic examination in adults: recommendations from the American society of echocardiography. J Am Soc Echocardiogr 32:1-64. https://doi.org/10.1016/j.echo.2018.06.004

5. Zoghbi WA, Adams D, Bonow RO, Enriquez-Sarano M, Foster E, Grayburn PA, Hahn RT, Han Y, Hung J, Lang RM, Little SH, Shah DJ, Shernan S, Thavendiranathan P, Thomas JD, Weissman NJ (2017) Recommendations for noninvasive evaluation of native valvular regurgitation: a report from the American society of echocardiography developed in collaboration with the society for cardiovascular magnetic resonance. J Am Soc Echocardiogr 30:303-371. https://doi.org/10.1016/j.echo.2017.01.007 
6. Baumgartner H, Kratzer H, Helmreich G, Kuehn P (1990) Determination of aortic valve area by Doppler echocardiography using the continuity equation: a critical evaluation. Cardiology 77:101111. https://doi.org/10.1159/000174590

7. Griffith MJ, Carey C, Coltart DJ, Jenkins BS, Webb-Peploe MM (1989) Inaccuracies in using aortic valve gradients alone to grade severity of aortic stenosis. Br Heart J 62:372-378. https://doi. org/10.1136/hrt.62.5.372

8. Harrison MR, Gurley JC, Smith MD, Grayburn PA, DeMaria AN (1988) A practical application of Doppler echocardiography for the assessment of severity of aortic stenosis. Am Heart J 115:622-628

9. Michelena HI, Margaryan E, Miller FA, Eleid M, Maalouf J, Suri R, Messika-Zeitoun D, Pellikka PA, Enriquez-Sarano M (2013) Inconsistent echocardiographic grading of aortic stenosis: is the left ventricular outflow tract important? Heart 99:921-931. https ://doi.org/10.1136/heartjnl-2012-302881

10. Baumgartner H, Otto CM (2009) Aortic stenosis severity: do we need a new concept? J Am Coll Cardiol 54:1012-1013. https:// doi.org/10.1016/j.jacc.2009.05.040

11. Iribarne A, Easterwood RM, Bostock IC, McCullough JN (2017) Outcomes with moderate aortic stenosis and impaired left ventricular function: prelude to a randomized trial? J Thorac Dis 9:3529-3532. https://doi.org/10.21037/jtd.2017.09.16

12. Lancellotti P, Magne J, Donal E, Davin L, O’Connor K, Rosca M, Szymanski C, Cosyns B, Piérard LA (2012) Clinical outcome in asymptomatic severe aortic stenosis: insights from the new proposed aortic stenosis grading classification. J Am Coll Cardiol 59:235-243. https://doi.org/10.1016/j.jacc.2011.08.072

13. Zoghbi WA, Farmer KL, Soto JG, Nelson JG, Quinones MA (1986) Accurate noninvasive quantification of stenotic aortic valve area by Doppler echocardiography. Circulation 73:452-459

14. Gaede L, Blumenstein J, Liebetrau C, Dörr O, Kim WK, Nef H, Husser O, Gülker J, Elsässer A, Hamm CW, Achenbach S, Möllmann H (2019) Transvascular transcatheter aortic valve implantation in 2017. Clin Res Cardiol. https://doi.org/10.1007/s0039 2-019-01509-8(Epub ahead of print)

15. Kim WK, Hamm CW (2018) Transcatheter aortic valve implantation in Germany. Clin Res Cardiol 107(Suppl 2):81-87. https:// doi.org/10.1007/s00392-018-1297-0

16. Frank D, Abdel-Wahab M, Gilard M, Digne F, Souteyrand G, Caussin C, Collart F, Letocart V, Wöhrle J, Kuhn C, Hovorka T, Baumgartner H (2019) Characteristics and outcomes of patients $\leq 75$ years who underwent transcatheter aortic valve implantation: insights from the SOURCE 3 registry. Clin Res Cardiol 108(7):763-771. https://doi.org/10.1007/s00392-018-14042PMID: 30552511

17. Ito S, Miranda WR, Nkomo VT, Connolly HM, Pislaru SV, Greason KL, Pellikka PA, Lewis BR, Oh JK (2018) Reduced left ventricular ejection fraction in patients with aortic stenosis. J Am Coll Cardiol 71:1313-1321. https://doi.org/10.1016/j.jacc.2018.01.045

18. Kadem L, Dumesnil JG, Rieu R, Durand LG, Garcia D, Pibarot $\mathrm{P}$ (2005) Impact of systemic hypertension on the assessment of aortic stenosis. Heart 91(3):354-361. https://doi.org/10.1136/ hrt.2003.030601

19. Little SH, Chan KL, Burwash IG (2007) Impact of blood pressure on the Doppler echocardiographic assessment of severity of aortic stenosis. Heart 93:848-855. https://doi.org/10.1136/ hrt.2006.098392

20. Gotzmann M, Hauptmann S, Hogeweg M, Choudhury DS, Schiedat F, Dietrich JW, Westhoff TH, Bergbauer M, Mügge A (2019) Hemodynamics of paradoxical severe aortic stenosis: insight from a pressure-volume loop analysis. Clin Res Cardiol. https://doi. org/10.1007/s00392-019-01423-z(Epub ahead of print)

21. Bach DS (2010) Echo/Doppler evaluation of hemodynamics after aortic valve replacement: principles of interrogation and evaluation of high gradients. JACC Cardiovasc Imaging. 3:296304. https://doi.org/10.1016/j.jcmg.2009.11.009

22. Bahlmann E, Cramariuc D, Gerdts E, Gohlke-Baerwolf C, Nienaber CA, Eriksen E, Wachtell K, Chambers J, Kuck KH, Ray S (2010) Impact of pressure recovery on echocardiographic assessment of asymptomatic aortic stenosis: a SEAS substudy. JACC Cardiovasc Imaging. 3:555-562. https://doi.org/10.1016/j. jemg.2009.11.019

23. Baumgartner H, Stefenelli T, Niederberger J, Schima H, Maurer G (1999) "Overestimation" of catheter gradients by Doppler ultrasound in patients with aortic stenosis: a predictable manifestation of pressure recovery. J Am Coll Cardiol 33:1655-1661

24. Chin CWL, Khaw HJ, Luo E, Tan S, BSc, White AC, Newby DE, Dweck MR, (2014) Echocardiography underestimates stroke volume and aortic valve area: implications for patients with smallarea low-gradient aortic stenosis. Can J Cardiol 30:1064-1072. https://doi.org/10.1016/j.cjca.2014.04.021

25. Laskey WK, Kussmaul WG (1994) Pressure recovery in aortic valve stenosis. Circulation 89:116-121

26. Altiok E, Koos R, Schröder J, Brehmer K, Hamada S, Becker M, Mahnken AH, Almalla M, Dohmen G, Autschbach R, Marx N, Hoffmann R (2011) Comparison of two-dimensional and threedimensional imaging techniques for measurement of aortic annulus diameters before transcatheter aortic valve implantation. Heart 97:1578-1584. https://doi.org/10.1136/hrt.2011.223974

27. Clavel M-A, Malouf J, Messika-Zeitoun D, Araoz PA, Michelena HI, Enriquez-Sarano M (2015) Aortic valve area calculation in aortic stenosis by CT and Doppler echocardiography. JACC 8:248-257. https://doi.org/10.1016/j.jcmg.2015.01.009

28. LaBounty TM, Miyasaka R, Chetcuti S, Grossman PM, Deeb GM, Patel HJ, Booher A, Patel S, Bach DS (2014) Annulus instead of LVOT diameter improves agreement between echocardiography effective orifice area and invasive aortic valve area. JACC 7:1065-1066. https://doi.org/10.1016/j.jcmg.2014.03.021

29. Leye M, Brochet E, Lepage L, Cueff C, Boutron I, Detaint D, Hyafil F, Iung B, Vahanian A, Messika-Zeitoun D (2009) Sizeadjusted left ventricular outflow tract diameter reference values: a safeguard for the evaluation of the severity of aortic stenosis. J Am Soc Echocardiogr 22:445-451. https://doi.org/10.1016/j. echo.2009.02.007

30. Nakai H, Takeuchi M, Yoshitani H, Kaku K, Haruki N, Otsuji Y (2010) Pitfalls of anatomical aortic valve area measurements using two-dimensional transoesophageal echocardiography and the potential of three-dimensional transoesophageal echocardiography. Eur J Echocardiogr 11:369-376. https://doi.org/10.1093/ ejechocard/jep220

31. Poh KK, Levine RA, Solis J, Shen L, Flaherty M, Kang YJ, Guerrero JL, Hung J (2008) Assessing aortic valve area in aortic stenosis by continuity equation: a novel approach using real-time three-dimensional echocardiography. Eur Heart J 29:2526-2535. https://doi.org/10.1093/eurheartj/ehn022

32. Biner S, Rafique AM, Goykhman P, Morrissey RP, Naghi J, Siegel $R J$ (2010) Prognostic value of E/E' ratio in patients with unoperated severe aortic stenosis. JACC Cardiovasc Imaging. 3:899-907. https://doi.org/10.1016/j.jcmg.2010.07.005-10

33. Melby SJ, Moon MR, Lindman BR, Bailey MS, Hill LL, Damiano RJ Jr (2011) Impact of pulmonary hypertension on outcomes after aortic valve replacement for aortic valve stenosis. J Thorac Cardiovasc Surg 141:1424-1430. https://doi.org/10.1016/j.jtcvs .2011 .02 .028

34. Rader F, Sachdev E, Arsanjani R, Siegel RJ (2015) Left ventricular hypertrophy in valvular aortic stenosis: mechanisms and clinical implications. Am J Med. 128:344-352. https://doi. org/10.1016/j.amjmed.2014.10.054

35. Rosenhek R, Klaar U, Schemper M, Scholten C, Heger M, Gabriel H, Binder T, Maurer G, Baumgartner H (2004) Mild and moderate 
aortic stenosis. Natural history and risk stratification by echocardiography. Eur Heart J 25:199-205

36. Zuern CS, Eick C, Rizas K, Stoleriu C, Woernle B, Wildhirt S, Herdeg C, Stock U, Gawaz M, Bauer A (2012) Prognostic value of mild-to-moderate pulmonary hypertension in patients with severe aortic valve stenosis undergoing aortic valve replacement. Clin Res Cardiol 101:81-88. https://doi.org/10.1007/s0039 2-011-0367-3

37. Hachicha Z, Dumesnil JG, Pibarot P (2009) Usefulness of the valvuloarterial impedance to predict adverse outcome in asymptomatic aortic stenosis. J Am Coll Cardiol 54:1003-1011. https ://doi.org/10.1016/j.jacc.2009.04.079

38. Lancellotti P, Magne J (2011) Valvuloarterial impedance in aortic stenosis: look at the load, but do not forget the flow. Eur J Echocardiogr 12:354-357. https://doi.org/10.1093/ejechocard/ jer044

39. Hu K, Liu D, Herrmann S, Niemann M, Gaudron PD, Voelker W, Ertl G, Bijnens B, Weidemann F (2013) Clinical implication of mitral annular plane systolic excursion for patients with cardiovascular disease. Eur Heart J Cardiovasc Imaging 14:205-212. https://doi.org/10.1093/ehjci/jes240

40. Matos JD, Kiss JE, Locke AH, Goldberg RI, Mukamal K, Manning WJ (2017) Relation of the mitral mitral annular plane systolic excursion to risk for intervention in initially asymptomatic patients with aortic stenosis and preserved systolic function. Am J Cardiol 120(11):2031-2034. https://doi.org/10.1016/j.amjca rd.2017.08.021

41. Rydberg E, Gudmundsson P, Kennedy L, Erhardt L, Willenheimer R (2004) Left atrioventricular plane displacement but not left ventricular ejection fraction is influenced by the degree of aortic stenosis. Heart 90(10):1151-1155. https://doi.org/10.1136/ hrt.2003.020628

42. Weidemann F, Herrmann S, Störk S, Niemann M, Frantz S, Lange V, Beer M, Gattenlöhner S, Voelker W, Ertl G, Strotmann JM (2009) Impact of myocardial fibrosis in patients with symptomatic severe aortic stenosis. Circulation 120:577-584. https://doi. org/10.1161/CIRCULATIONAHA.108.847772

43. Eleid MF, Sorajja P, Michelena HI, Malouf JF, Scott CG, Pellikka PA (2013) Flow-gradient patterns in severe aortic stenosis with preserved ejection fraction: clinical characteristics and predictors of survival. Circulation 128:1781-1789. https://doi.org/10.1161/ CIRCULATIONAHA.113.003695

44. Rosenhek R, Zilberszac R, Schemper M, Czerny M, Mundigler G, Graf S, Bergler-Klein J, Grimm M, Gabriel H, Maurer G (2010) Natural history of very severe aortic stenosis. Circulation 121:151-156. https://doi.org/10.1161/CIRCULATIO NAHA.109.894170

45. Ross J Jr, Braunwald E (1968) Aortic stenosis. Circulation 38(1 Suppl):61-67

46. Tribouilloy C, Lévy F, Rusinaru D, Guéret P, Petit-Eisenmann H, Baleynaud S, Jobic Y, Adams C, Lelong B, Pasquet A, Chauvel C, Metz D, Quéré JP, Monin JL (2009) Outcome after aortic valve replacement for low-flow/low-gradient aortic stenosis without contractile reserve on dobutamine stress echocardiography. J Am Coll Cardiol 53:1865-1873. https://doi.org/10.1016/j. jacc.2009.02.026

47. Jander N, Minners J, Holme I, Gerdts E, Boman K, Brudi P, Chambers JB, Egstrup K, Kesäniemi YA, Malbecq W, Nienaber CA, Ray S, Rossebø A, Pedersen TR, Skjærpe T, Willenheimer R, Wachtell K, Neumann FJ, Gohlke-Bärwolf C (2011) Outcome of patients with low-gradient "severe" aortic stenosis and preserved ejection fraction. Circulation 123:887-895. https://doi. org/10.1161/CIRCULATIONAHA. 110.983510

48. Lancellotti P, Magne J, Dulgheru R, Clavel MA, Donal E, Vannan MA, Chambers J, Rosenhek R, Habib G, Lloyd G, Nistri S, Garbi M, Marchetta S, Fattouch K, Coisne A, Montaigne D,
Modine T, Davin L, Gach O, Radermecker M, Liu S, Gillam L, Rossi A, Galli E, Ilardi F, Tastet L, Capoulade R, Zilberszac R, Vollema EM, Delgado V, Cosyns B, Lafitte S, Bernard A, Pierard LA, Bax JJ, Pibarot P, Oury C (2018) Outcomes of patients with asymptomatic aortic stenosis followed up in heart valve clinics. JAMA Cardiol 3:1060-1068. https://doi. org/10.1001/jamacardio.2018.3152

49. Monin JL, Quéré JP, Monchi M, Petit H, Baleynaud S, Chauvel C, Pop C, Ohlmann P, Lelguen C, Dehant P, Tribouilloy C, Guéret P (2003) Low-gradient aortic stenosis: operative risk stratification and predictors for long-term outcome: a multicenter study using dobutamine stress hemodynamics. Circulation 108:319-324. https ://doi.org/10.1161/01.CIR.0000079171.43055.46

50. Rosenhek R, Binder T, Porenta G, Lang I, Christ G, Schemper M, Maurer G, Baumgartner H (2000) Predictors of outcome in severe, asymptomatic aortic stenosis. N Engl J Med 343:611-617

51. Clavel MA, Dumesnil JG, Capoulade R, Mathieu P, Sénéchal M, Pibarot P (2012) Outcome of patients with aortic stenosis, small valve area, and low-flow, low-gradient despite preserved left ventricular ejection fraction. J Am Coll Cardiol 60:1259-1267. https ://doi.org/10.1016/j.jacc.2011.12.054

52. Dumesnil JG, Pibarot P, Carabello B (2010) Paradoxical low flow and/or low gradient severeaortic stenosis despite preserved left ventricularejection fraction: implications for diagnosisand treatment. Eur Heart J 31: 281-289. https://doi.org/10.1093/eurheartj/ ehp361

53. Herrmann S, Stork S, Niemann M, Lange V, Strotmann JM, Frantz S, Beer M, Gattenlohner S, Voelker W, Ertl G, Weidemann F (2011) Low-gradient aortic valve stenosis myocardial fibrosis and its influence on function and outcome. J Am Coll Cardiol 58:402-412. https://doi.org/10.1016/j.jacc.2011.02.059

54. Doenst T, Kirov H, Moschovas A, Gonzalez-Lopez D, Safarov R, Diab M, Bargenda S, Faerber G (2018) Cardiac surgery 2017 reviewed. Clin Res Cardiol 107(12):1087-1102. https://doi. org/10.1007/s00392-018-1280-9PMID: 29777372

55. Doenst T, Bargenda S, Kirov H, Moschovas A, Tkebuchava S, Safarov R, Diab M, Faerber G (2019) Cardiac surgery 2018 reviewed. Clin Res Cardiol. https://doi.org/10.1007/s00392-01901470-6 (Epub ahead of print)

56. Barone-Rochette G, Piérard S, Seldrum S, de Meester de Ravenstein C, Melchior J, Maes F, Pouleur AC, Vancraeynest D, Pasquet A, Vanoverschelde JL, Gerber BL, (2013) Aortic valve area, stroke volume, left ventricular hypertrophy, remodeling, and fibrosis in aortic stenosis assessed by cardiac magnetic resonance imaging: comparison between high and low gradient and normal and low flow aortic stenosis. Circ Cardiovasc Imaging 6:1009-1017. https ://doi.org/10.1161/CIRCIMAGING.113.000515

57. Clavel MA, Burwash IG, Pibarot P (2017) Cardiac imaging for assessing low-gradient severe aortic stenosis. JACC Cardiovasc Imaging 10:185-202. https://doi.org/10.1016/j.jcmg.2017.01.002

58. Milano AD, Faggian G, Dodonov M, Golia G, Tomezzoli A, Bortolotti U, Mazzucco A (2012) Prognostic value of myocardial fibrosis in patients with severe aortic valve stenosis. J Thorac Cardiovasc Surg 144:830-837. https://doi.org/10.1016/j.jtcvs .2011.11.024

59. Ng AC, Delgado V, Bertini M, Antoni ML, van Bommel RJ, van Rijnsoever EP, van der Kley F, Ewe SH, Witkowski T, Auger D, Nucifora G, Schuijf JD, Poldermans D, Leung DY, Schalij MJ, Bax JJ (2011) Alterations in multidirectional myocardial functions in patients with aortic stenosis and preserved ejection fraction: a two-dimensional speckle tracking analysis. Eur Heart J 32:1542-1550. https://doi.org/10.1093/eurheartj/ehr084

60. Magne J, Cosyns B, Popescu BA, Carstensen HG, Dahl J, Desai MY, Kearney L, Lancellotti P, Marwick TH, Sato K, Takeuchi M, Zito C, Casalta AC, Mohty D, Piérard L, Habib G, Donal E (2019) Distribution and prognostic significance of left ventricular global 
longitudinal strain in asymptomatic significant aortic stenosis: an individual participant data meta-analysis. JACC Cardiovasc Imaging 12:84-92. https://doi.org/10.1016/j.jcmg.2018.11.005

61. de Marchi SF, Windecker S, Aeschbacher BC, Seiler C (1999) Influence of left ventricular relaxation on the pressure half time of aortic regurgitation. Heart 82:607-613. https://doi.org/10.1136/ hrt.82.5.607

62. Egbe AC, Luis SA, Padang R, Warnes CA (2016) Outcomes in moderate mixed aortic valve disease. J Am Coll Cardiol 67:23212329. https://doi.org/10.1016/j.jacc.2016.03.509-17

63. Zilberszac R, Gabriel H, Schemper M, Zahler D, Czerny M, Maurer G, Rosenhek R (2013) Outcome of combined stenotic and regurgitant aortic valve disease. J Am Coll Cardiol 61:1489-1495. https://doi.org/10.1016/j.jacc.2012.11.070
64. Ewen S, Karliova I, Weber P, Schirmer SH, Abdul-Khaliq H, Schope J, Mahfoud F, Schafers HJ (2019) Echocardiographic criteria to detect unicuspid aortic valve morphology. Eur Heart J Cardiovasc Imaging 20:40-44. https://doi.org/10.1093/ehjci/jex34 4

65. Loukas M, Bilinsky E, Bilinsky S, Blaak C, Tubbs RS, Anderson RH (2014) The anatomy of the aortic root. Clin Anat 27:748-756. https://doi.org/10.1002/ca.22295

66. Minners J, Allgeier M, Gohlke-Baerwolf C, Kienzle RP, Neumann FJ, Jander N (2008) Inconsistencies of echocardiographic criteria for the grading of aortic valve stenosis. Eur Heart J 29:1043-1048. https://doi.org/10.1093/eurheartj/ehm543 